\title{
Social Influence and the Autism Epidemic ${ }^{1}$
}

\author{
Ka-Yuet Liu, Marissa King, and Peter S. Bearman \\ Columbia University
}

\begin{abstract}
Despite a plethora of studies, we do not know why autism incidence has increased rapidly over the past two decades. Using California data, this study shows that children living very close to a child previously diagnosed with autism are more likely to be diagnosed with autism. An underlying social influence mechanism involving information diffusion drives this result, contributing to $16 \%$ of the increase in prevalence over 2000-2005. We eliminate competing explanations (i.e., residential sorting, environmental toxicants, and viral transmission) through seven tests and show that information diffusion simultaneously contributed to the increased prevalence, spatial clustering, and decreasing age of diagnosis.
\end{abstract}

\section{INTRODUCTION}

Autism is a developmental disorder characterized by impairments in social interaction and communication, often accompanied by stereotypical or repetitive behaviors. As there are no definitive biological markers for the vast majority of cases, diagnosis relies on the recognition of a range of behavioral symptoms that vary greatly from case to case, that are increasingly heterogeneous, that are more difficult to isolate because age of diagnosis has declined, and that overlap with those of other childhood neuropsychiatric disorders. Despite hundreds of studies, we still do not know why autism incidence increased rapidly during the 1990s (Croen et al. 2002) or why increased incidence is associated with marked spatial clustering (Mazumdar et al. 2010). In this article, we identify a central

\footnotetext{
${ }^{1}$ Hannah Brückner, Nicholas Christakis, Diana Dakhlallah, Mitch Duneier, Christine Fountain, Roy Grinker, Thomas Insel, Bruce Link, Soumya Mazumdar, Bernice Pescosolido, Robert Sampson, Patrick Sharkey, Seymour Spilerman, Ezra Susser, and Noam Zerubavel provided enormously useful assistance for which we are deeply grateful, as did the $A J S$ reviewers. This research is supported by the National Institutes of Health (NIH) Director's Pioneer Award program, part of the NIH Roadmap for Medical Research (grant 1 DP1 OD003635-01). Direct correspondence to Peter S. Bearman, Paul F. Lazarsfeld Center for the Social Sciences, CB3355, Columbia University, New York, New York 10027. E-mail: psb17@columbia.edu
}

(C) 2010 by The University of Chicago. All rights reserved. 0002-9602/2010/11505-0002\$10.00

AJS Volume 115 Number 5 (March 2010): 1387-1434 
mechanism that yields the increased prevalence and spatial clustering of measured autism and the decreasing age of diagnosis.

Substantial resources flow to families for the treatment of children diagnosed with autism - significantly more than for other childhood neuropsychiatric and developmental disorders. ${ }^{2}$ But in order to secure these resources for their children, parents have to recognize the behavioral symptoms of autism, identify and reach a physician capable of identifying autism, and learn how to navigate the complex world of state developmental service departments, school systems, and other service vendors. Obviously, this knowledge is achieved, not ascribed. Anecdotal evidence indicates that one of the ways in which parents learn how to navigate the world of autism is from other parents (Grinker 2007). In other areas of health and medicine, the influence of community-based interpersonal social networks on individuals' recognition and response to the onset of symptoms has been well documented (see Pescosolido and Levy [2002] and Rogers [2003] for reviews). It follows that parental awareness of autism and knowledge about strategies to secure resources for their children is likely to depend strongly on social interactions within the local social networks in which families are embedded (Pescosolido 1992). These social networks arise out of focal points for interaction that are centered in neighborhoods-from close neighbors to neighborhood parks, stores, and preschools (Feld 1981; Feld and Grofman 2009).

In this article, we show that children living in very close proximity to a child previously diagnosed with autism are significantly more likely to be diagnosed with autism than are comparable children who lack such exposure. ${ }^{3}$ This fact could arise from four main sources: from shared toxicants, through the diffusion of a virus, as a by-product of neighborhood selection, or through the diffusion of information about autism

\footnotetext{
${ }^{2}$ It is estimated to cost about $\$ 3.2$ million to provide care for a person with autism over his or her lifetime, and caring for all people with autism in the United States costs roughly $\$ 35$ billion per year. When only school costs are considered, the average per-pupil expenditures for people with autism was $\$ 18,000$, compared with $\$ 12,500$ for other special education students (GAO 2006).

${ }^{3}$ Children in our sample are diagnosed with autism between the ages of two and six, and they live with their parents when this occurs. Consequently, one could alternatively say that parents of children age two to six living in very close proximity to other parents with a child in the same age range previously diagnosed with autism are significantly more likely to have their children diagnosed with autism than are comparable parents who lack such exposure. The mechanism under study in this article focuses on parental interactions, not interactions among children, and the formulation we use-children living in close proximity to other children - is selected for brevity of expression.
} 
through social networks. ${ }^{4}$ First, an environmental toxicant could be associated with increased risk of autism, and so a shared toxicological environment could create similar risks to children living near one another. This would be an environmental effect, if present. Second, the effect could be caused by the diffusion of a virus that was associated with autism either directly or indirectly by altering maternal immune response during pregnancy (Ashwood and Van de Water 2004), the period most important to neurological development (Grandjean and Landrigan 2006). Independent of the specific mechanism, this would be a viral effect, if present. A third mechanism could be compositional—specifically, known risk factors for autism may cluster within neighborhoods through selection dynamics. If parents at greater risk for a child with autism selected a particular kind of neighborhood to reside in, selection would account for the microlevel spatial clustering of autism. In fact, residential selection and sorting mechanisms do induce clustering on many risk factors for autism-this is the case for socioeconomic status, parental age, and access to health-care resources-all of which structure residential choices and are associated with autism (Massey and Denton 2001; Morenoff 2003; King and Bearman $2009 b) .{ }^{5}$ Finally, meeting children with autism and having discussions with parents of children with autism could lead parents (of children not diagnosed with autism) to observe behavioral symptoms consistent with autism, to learn how to effectively identify and reach a physician, and to learn how to access and subsequently navigate services and service agencies. If these dynamics were at play, this would be a social influence effect.

There is widespread recognition in everyday circles that the measured prevalence of autism has increased dramatically over the past two decades. Nationwide, the prevalence of autism has increased from 4 cases per 10,000 people in 1989 to 67 cases per 10,000 people in 2000 (Ritvo et al. 1989; CDC 2007). In California-where autism prevalence is lower than the national average - the number of autism cases handled by the California Department of Developmental Services increased 634\% between 1987 and 2003 (California Department of Developmental Services 2003). Whether these increases signify an "epidemic" or an "epidemic of discovery" (Grinker 2007) can be debated, but what is not really debatable is that the increase in autism incidence is very large, people now think about autism as part of the developmental landscape, and information

\footnotetext{
${ }^{4}$ Also for the sake of brevity, we use the term "virus" throughout this article to refer to any infectious agent (e.g., bacteria, protozoa) that could be spread between persons in close proximity.

${ }^{5}$ If information exchange is a core mechanism by which autism diagnoses diffuse across persons-as we show here-then these risk factors (many of which are not associated with a clear mechanism for "getting under the skin") could be purely artifactual, which we suspect to be the case.
} 
about autism treatments and causes is now widespread. ${ }^{6}$ It is perhaps simple enough to say that beyond the stratospheric discussions of academics, autism increasingly appears in the everyday life of American families. Every hour in the United States, three children are diagnosed with autism.

Consequently, disentangling these competing accounts-whether the increase in measured prevalence, the spatial clustering of autism cases, and the shifting distribution of case severity arise from social influence, toxicological change, or viral transmission-is more than a simple intellectual exercise. In this article, we design a data structure and a series of critical tests to disentangle these explanations. To anticipate the main finding, our observations are consistent with a social influence process and inconsistent with other explanations.

Diagnostic Ambiguity, Increased Attention, and the Difficulty of Getting a Diagnosis

In the absence of unambiguous markers for autism, diagnosis is based primarily on the recognition and interpretation of behavioral symptoms. As autism incidence has increased, the behavioral symptoms associated with an autism diagnosis have become increasingly heterogeneous (Eyal et al., in press). As Eyal and others have noted, the increasing heterogeneity of autism is encoded in a series of diagnostic changes built into the very idea of a spectrum. In the present context, symptoms vary widely across the autism spectrum and overlap markedly with other neurodevelopmental disorders. ${ }^{7}$ Making sense of the role that increasing heterogeneity —and diagnostic expansion—of autism has played in increasing prevalence has become a cottage industry. King and Bearman (2009a) show that roughly $25 \%$ of the increased caseload in California arises from diagnostic change on the mental retardation (MR) pathway-specifically, the accretion of autism diagnoses yielding autism-MR comorbidity. More difficult is the estimation of the role that diagnostic expansion has played on the less severe side of the spectrum. ${ }^{8}$ A disproportionate share of the increased autism caseload in California (the setting from which our data

\footnotetext{
${ }^{6}$ A Google search of "autism treatments" returns more than 2 million results, "autism rates" returns over 4 million, and "autism" returns over 15 million.

${ }^{7}$ In this article we consider only autism, not "autism spectrum disorders," which also include pervasive developmental disorder, not otherwise specified (PDD-NOS), Asperger's syndrome, and Rett's disorder. Even within this more limited diagnostic framework, symptom heterogeneity is marked.

${ }^{8}$ We use the two concepts of "severity" and "functioning" as interchangeable here. Thus, low severity is associated with high functioning, and vice versa.
} 
are drawn) arises from the tails of this distribution, most markedly on the high-functioning tail.

If two decades ago the boundary between MR and autism was the most blurred, this is now the case for the highest-functioning autism, which diagnostically overlaps most with other disorders on the autism spectrum-PDD-NOS and Asperger's syndrome-as well as learning disorders more generally. Even where considerable scientific care is exercised across multiple assessment tools, diagnostic ambiguity on the high end is striking. Charman et al. (2009, p. 1236), for example, report that "within our own study where all design and methodological factors are invariant, our prevalence estimates varied by up to 4.5 times from the strictest to the least demanding set of diagnostic criteria." Thus, for both those on the MR-autism border and those in the highest-functioning range, finding the right diagnostician and accessing the right service providers are likely strongly related to the probability of acquiring an autism diagnosis.

Children diagnosed with autism who have severe disability are more similar to those whose primary diagnosis is (etiologically unknown) MR. In our data, the symptom-expression overlap can be observed by noting that the assessment scores for autism symptoms at first diagnosis for individuals with only an MR diagnosis completely envelop those for individuals with a full-syndrome autism diagnosis. As with the high-functioning end of the distribution, differential diagnosis between autism and MR can be difficult, particularly in young children. Overlapping severity scores (from observation of behavioral symptoms) at first diagnosis between autism and MR confirm the shady boundary for those children whose MR - should it be diagnosed-is of unknown etiology. The fact that diagnosis on the border can be difficult is compounded by differential attention dynamics associated with MR and autism and differential benefits arising for children with autism relative to those with MR (Goffman 1963; Link and Phelan 2001). While autism was highly stigmatized before the 1970s, with increasing attention this situation appears to have changed radically.

We know very little about the process by which autism diagnoses are obtained, other than from a scattering of autobiographical accounts and selective parent surveys. All of these, however, suggest that diagnoses can be excruciatingly difficult to obtain. ${ }^{9}$ For instance, one decade-old survey found that upon first consultation, parents of children with autism were three times more likely to be told that there was "no problem [with their child]" than to be given a diagnosis (Howlin and Moorf 1997). In the 10 years since that survey was administered, the situation has improved for

\footnotetext{
${ }^{9}$ This could be a product of selection. Those who had an easy time would have less interesting accounts and so less motivation to tell them.
} 
older children whose presentation at first diagnosis is most severe, which suggests that the community and school-based ascertainment regime is able to identify and secure treatment for children most affected by autism (Howlin and Asgharian 1999; Eyal et al., in press). These developments notwithstanding, parents of younger children whose presentation is less clear rely on information from other parents as their most effective guides. For example, one mother of young twins residing in California reported, "My neighbor gave me the name of the only doctor in [town name deleted] who would give my son an autism diagnosis" (personal correspondence, February 10, 2008). This sentiment was echoed in numerous parent-based autism support groups.

If parents now seek information to more efficiently secure a diagnosis of autism, the historical pattern was the obverse. For several decades after its initial identification in 1943, autism was thought to be the by-product of the response of children to the double bind of cold and ineffective parenting, a view initially promoted by Kanner (1949) and later by Bettelheim (1967) with the imagery of the "refrigerator mother." Throughout the 1950s and 1960s, whole generations of American parents of children with autism suffered stigmatization (Bettelheim 1967). As noted earlier, conversely and simultaneously, MR was losing much of its stigma as a powerful advocacy movement took hold and garnered a wealth of resources for people with MR. In this regard, MR advocates pioneered a resource niche for people with developmental disabilities. Between 1948 and 1966, the number of children with MR in public school classrooms increased by a factor of five because of the political and administrative success of MR advocates in securing special education classes (Trent 1994). In 1973, the Rehabilitation Act, a precursor to the Individuals with Disabilities Education Act, guaranteed the right to an appropriate education for people with a recognized disability, which included MR but not autism. In addition, Medicaid and Medicare coverage, Supplemental Security Income, and a guarantee of services were secured (Eyal et al., in press). While MR advocates were making progress in securing rights and benefits for people with MR, virtually no resources were available to individuals with autism. Autism was not excluded by omission—rather, MR advocates worked hard to ensure that autism was disqualified from federal legislation (Sullivan 1979).

With hindsight, we can recognize that autism was increasingly destigmatized through the mobilization efforts of Bernard Rimland and the National Society for Autistic Children (NSAC), whose work refuted psychogenic theories of autism and set the stage for the research program that would identify autism as a neurological disorder (Dolnick 1998). Deploying mounting empirical evidence, NSAC was able to ensure that autism was recognized in the Developmental Disability Act reauthor- 
ization. In the decades to follow, two processes already underway were sewn up, allowing the autism and MR stigmas to reverse. First, autism was successfully reclassified from a severe emotional disorder to a developmental disability. Second, resources directed to autism research and treatment and care for individuals with autism expanded radically, fueled both by increasing autism prevalence and an expanding advocacy effort. For example, in 2006, the revenue raised by the largest autism advocacy organization was nearly 10 times the funding reaped by the largest intellectual disability organization, despite the higher prevalence of MR (\$33 million vs. \$3.4 million; National Center for Charitable Statistics 2008). In the research world, CDC funding of autism activities increased from $\$ 2.1$ million in 2000 to about $\$ 16.7$ million in 2005 (GAO 2006), and National Institutes of Health funding for autism increased more than fourfold, from \$22 million in 1997 to $\$ 108$ million in 2007 (Nature 2007). In contrast, total public financial support for MR increased only $16 \%$ between 2000 and 2004 (Braddock 2007).

The relative destigmatization of autism and the enhanced resources devoted to understanding autism etiology, treatment, and education meant that parents who in the 1960s and 1970s may have deployed their resources to avoid a stigmatized autism diagnosis no longer needed to do so. ${ }^{10}$ In fact, facing likely strong incentives for an autism diagnosis, parents seeking to provide benefits to their children would have reason to deploy their resources for an autism diagnosis. But having resources and knowing how to deploy them are two different things. Here we provide evidence that knowledge diffuses through local social networks, enabling parents to effectively deploy resources, including but not limited to finding (and collaborating with) physicians whose diagnostic practices are long known to be influenced by patient understandings (cf. Freidson [1961] for the classic argument).

\section{Spatial Distance and Social Interactions}

Social interactions are strongly conditioned by the spatial distance between individuals (Festinger, Schachter, and Back 1950; Haynes 1974; Gonzalez, Hidalgo, and Barabasi 2008). In this context, the relevant interactions are between parents of young children and other parents of young children, where conversation turns to shared interests such as child

\footnotetext{
${ }^{10}$ The strong positive association of autism (during the period of increasing prevalence, 1992-2000) with socioeconomic status (King and Bearman 2009b), coupled with the increasingly negative socioeconomic status gradient for MR (arising from differential abortion rates for fetuses identified as chromosomally damaged through amniocentesis), has led to a relative stigma reversal and a consequent decline in the rate of MR diagnoses.
} 
development, pediatricians, sleep deprivation, and the like. Parents meet other parents at schools, shops, playgrounds, and other focal points, the vast majority of which are rooted in local communities (Fischer 1982; Huckfeldt 1983; Campbell and Lee 1992; Guest and Wierzbicki 1999; Small 2009). ${ }^{11}$ As a consequence, the movement of persons in their everyday life (not counting the commute to work, which can involve significant distance) tends to be highly spatially restricted. As a recent largescale study reports, human movement is characterized by a predominance of short-distance travel (Gonzalez et al. 2008). This feature of human activity fundamentally shapes our patterns of social interactions. There are reasons to expect that neighborhood interactions are important to parents with young children, net of the general finding that many interactions occur in delimited spatial context: observational data strongly suggest that parents of small children associate with other parents of small children at greater than expected rates. The typical distance that parents travel with their young children is limited. In the epicenter of our study area-Los Angeles, California - the vast majority (85\%) of adults define their neighborhood to be an area that is within a 15 -minute walk from home (approximately one kilometer to 0.68 miles), and having children is negatively associated with the size of the neighborhood reported (Sastry, Pebley, and Zonta 2002). Focal meeting points can typically be found within one to two kilometers in California: the median distance to the nearest playground or local park or preschool is 0.7 kilometers, and the distance to the nearest pediatrician is 1.1 kilometers (see table 1). Given the spatial structuring of interactions, if information about autism is flowing through interpersonal networks, close proximity to a child with autism should increase the likelihood of information diffusion (Rogers 2003).

Disentangling Social, Viral, Environmental, or Compositional Causes of Spatial Clustering

The tails of the autism severity distribution have increased the most precipitously. Specifically, holding the 1992 severity distribution constant, we can observe that the proportion of children scoring above the first decile of the 1992 distribution has more than doubled, moving from 10\% (a mathematical truism) to $22 \%$. Likewise, the bottom decile of the severity distribution has increased $60 \%$ over the same period, covering the birth cohorts of 1992-2003. Consequently, any account of the mechanism by which autism prevalence has increased needs to explain simultaneous

${ }^{11}$ As any reader who has had small children knows from experience, the friendship networks of adults are increasingly filled up with the parents of their children's friends. This arises because of both common interests and common schedules (Winship 2009). 
Social Influence and Autism

TABLE 1

Spatial Distribution of Focal Points in California

\begin{tabular}{lcc}
\hline \hline & Median Distance & Interquartile Range \\
\hline Playground or local park $\ldots \ldots \ldots \ldots \ldots \ldots$ & $.7(.4)$ & $.0-1.1(.0-.7)$ \\
Preschool $\ldots \ldots \ldots \ldots \ldots \ldots \ldots \ldots \ldots \ldots \ldots \ldots$ & $.7(.4)$ & $.4-1.1(.2-.7)$ \\
Pediatrician $\ldots \ldots \ldots \ldots \ldots \ldots \ldots \ldots \ldots \ldots$ & $1.1(.7)$ & $.6-2.0(.4-1.3)$ \\
\hline
\end{tabular}

NotE.-Values are given in kilometers, with miles in parentheses. Median distances were calculated between the children's homes and their nearest playground or park, preschool, and pediatrician.

growth on both sides. This requirement is challenging. If a single mechanism were at play, it would have to operate disproportionately on the tails of the distribution and not on the middle. While this requirement does not rule out toxicants, viruses, or compositional effects, it raises the stakes for each of the explanations competing with information diffusion and sets up a series of tests - the results of which can point in one or another direction as the most likely. ${ }^{12}$

A social influence dynamic should drive autism diagnoses for children at both extremes of the severity distribution. For parents with children on the border of an autism-MR diagnosis, we expect that exposure to children (and their parents) with autism - who are perceived as having a greater chance for recovery and have greater access to resources and services-should be associated with a decreased likelihood of a sole MR diagnosis and an increased likelihood of an autism-MR diagnosis. With respect to the less severe tail of the distribution, social influence should play a significant role in diffusing information about symptoms, services, and access. The same information that helps parents understand how to secure the most advantageous opportunities for their children on the lowfunctioning tail of the distribution should operate to lead parents to obtain an autism diagnosis-rather than a diagnosis of PDD-NOS or the likeon the less severe side of the distribution. In sum, social influence is most likely to be observed for high- and low-functioning individuals, where interpretation of symptoms is most difficult, ascertainment from service agencies without parent agency is most unlikely, and knowledge of service systems and pediatricians is most important. In this regard, a social influence effect should be stronger for younger children (age 3) than for those who are school-age (ages 5-6), both because of the more ambiguous symptom presentation and the absence of institutional ascertainment.

${ }^{12}$ Here we are not suggesting that autism has a single cause-the disorder is complex and heterogeneous, and multiple drivers are likely operating. Our focus is to identify a central mechanism that can explain a significant component of the increased prevalence, the observation of spatial clustering, and the identification of increased risk of a subsequent autism diagnosis given residence near a child with autism. 
In contrast, the sociological null hypothesis-that microlevel spatial clustering of autism arises as an unintended by-product of residential sorting dynamics-does not make a prediction with respect to the probability of diagnosis and severity. If the proximity finding were driven by selection dynamics, spatial clustering would be uninformative, and individual-level risk factors for autism would be dispositive. We show that controlling for known individual-level and community-level risk factors for autism does not mitigate the increased probability of acquiring an autism diagnosis associated with living very close to a child with autism. Thus, our findings are not consistent with a compositional effect. They suggest, conversely, that the social characteristics seen as associated with autism for which there is no known mechanism are by-products of local diffusion dynamics. ${ }^{13}$

Falsifying the idea that spatial clustering of autism is the simple byproduct of residential sorting, however, does not help clarify whether the clustering of autism is associated with a localized environmental toxicant or the diffusion of a virus. Both toxicants and viruses could operate at the microlevel of the close neighborhood, and in fact we would expect virus diffusion to have a significant geographical foundation since viral transmission most routinely involves person-to-person contact (Klovdahl, Graviss, and Muser 2002). Turning to toxicants first, it is possible that a single toxicant could act largely on the tails of the severity distribution, but it is not likely. Environmental toxicity mechanisms do not have clear predictions concerning differential effects by severity; a single toxicant with such differential effects, operating at very local geographic scales, has not been identified for other developmental disorders. ${ }^{14}$ More problematic for an environmental toxicity account is the fact that the relationship we find between proximity and subsequent transition to autism is observed across a wide variety of neighborhoods-from those primarily agricultural to those primarily suburban, where the mix of toxicants present are quite different.

At first glance, viruses are more challenging, since they are passed from person to person through social contact, the same mechanism by which

\footnotetext{
${ }^{13}$ It is also the case that neighborhood selection dynamics likely operate at spatial resolutions larger than the effect we observe- - under 0.5 kilometers, which in a suburban setting is roughly 10-20 homes (the size of a large cul-de-sac). For parents, neighborhood selection operates on administratively salient units such as elementary school catchment boundaries or school districts, both of which are much larger than 0.5 kilometers (Saporito and Lareau 1999).

${ }^{14}$ Assuming that genetic susceptibility is distributed randomly across space and that toxicity decreases with distance from the source of toxicity, we should expect similarity of symptoms within rings of toxicity. This is also the expected pattern for a social influence dynamic.
} 
information is diffused. But a virus is very unlikely to cause a reduction of MR, so the negative impact of residing very close to a person with autism on the probability of a sole MR diagnosis cannot be ascribed to the operation of a virus. And as with an environmental toxicant, there is no reason to think that the effect of a virus would concentrate on the high-functioning tail of the severity distribution. Viruses and toxicants, all things equal, should express themselves across the severity spectrum.

In summary, it is difficult to disentangle local social influence from local environmental causation, but it is not impossible. Here we design a series of tests to identify mechanisms that can disentangle environmental and viral dynamics from social influence. By focusing on the microcontexts in which parents and children interact, we identify the mechanism by which social influence results in new diagnoses. Because knowledge about autism diffuses through local networks and increases the probability of diagnosis, local network dynamics are shown to be associated with the neighborhood clustering of autism (net of selection), the decreasing age of diagnosis, and the increased prevalence of autism.

\section{Road Map}

As noted earlier, alternative explanations to social influence that can generate an association between the proximity to a child with autism and subsequent diagnosis with autism need to be considered. In order to rule out compositional causation, we control for the effects of a range of variables measuring individual sociodemographic status and parental risk factors, autism service and advocacy organizations, pediatricians, and access to health-care resources. In order to eliminate the effect of unobserved variables, we then turn to a fixed-effects model. While environmental toxicity and viral mechanisms may explain the positive relationship between proximity and subsequent autism diagnosis, it is unlikely that they would lead to a change in the probability of a sole MR diagnosis. We thus consider the effects of close proximity to an individual with autism on the transition to sole MR. We show that proximity reduces sole MR diagnoses. The flip side of this argument is that the proximity effect should be particularly strong for a comorbid autism-MR diagnosis. We show that it is the case.

We then consider the severity of autism symptoms. A social diffusion process is more likely to affect nonsevere autism at first evaluation. In contrast, mechanisms based on the self-selection of high-risk parents to neighborhoods, environmental toxicity, and viral spread do not have clear predictions concerning such differential effects by severity. Our analyses show that the proximity effect is strongest for nonsevere autism cases. Using propensity score matching, we further show that when two children 
displayed the same level of autism symptoms, the one who lived closer to a child with autism was more likely to be subsequently diagnosed with autism, while the other was more likely to be diagnosed with sole MR.

We then consider age of diagnosis. Early diagnosis is believed to lead to better treatment outcomes, but it is also more difficult, given the greater variation in the level of development at a young age (Committee on Children with Disabilities 2001; Rutter 2006). Parents who have better access to information are more likely to ensure an early diagnosis than are those without access to information. As for the case of nonsevere autism, a proximity effect should matter most for early diagnoses, while it should be less important at a later developmental stage and when the child has entered the school system. This turns out to be the case.

The social diffusion of information should lead to similar referral sources (Granovetter 1995; Fernandez, Castilla, and Moore 2000), and we show that children who were diagnosed with autism were more likely to have the same referral source as their nearest neighbor with autism. There are no reasons why environmental toxicants or viruses should yield homophily of referral sources or should lead equally severely affected children to two different diagnoses depending on how far their nearest neighbor with autism lived.

Finally, we consider two additional tests that assess the robustness of the underlying social influence mechanism we identify. First, we conduct an "edge analysis" that allows us to exploit the fact that for some families, the nearest neighbor with autism resides in a different school district. Controlling for all of the individual and school district factors that are associated with autism ascertainment, we compare these families with families whose nearest neighbor with autism resides within the same school district. Environmental toxicants should be largely insensitive to social boundaries like school districts, but social influence should not be. We find that while parents' proximity to a child within their school district increases the chances that their child will be diagnosed with autism, equally close proximity across districts has no effect.

Second, we assess the sensitivity of social influence to duration of contact that arises from residential proximity. Movers into (and out of) communities should be less sensitive to social influence than stayers should, all things being equal. We consider how residential mobility affects exposure to children with autism (either because a child with autism moves and becomes a closest neighbor to a new child or because a family moves and is closer to a child with autism). As expected, duration of exposure is positively associated with increased risk of a subsequent autism diagnosis.

While our analyses do not prove that information diffusion yields autism diagnoses, the results are consistent with that hypothesis, hold across 
a series of robustness checks, and are consistent with a well-documented body of research that identifies a similar mechanism across a wide variety of lay responses to health problems (Pescosolido and Levy 2002). Information diffusion therefore provides a parsimonious account for three important observations: the spatial clustering, the earlier diagnoses, and the increased prevalence of autism. Finally, anticipating a central question to be considered later, the population attributable fraction associated with the dynamic we identify in this article is $16 \%$. Another way of thinking about this is that if this mechanism were absent, we would observe, at the least, a $16 \%$ decline in the autism caseload. We return to this issue in the discussion section, where we consider what piece of the pie social influence plays in the increased prevalence of measured autism.

\section{DATA AND METHODS}

Study Population

To examine the effect of the proximity to a child with autism on the chance of subsequent diagnosis, we need a longitudinal data set with detailed information on the geographical location of a large number of very young children. Such data are extremely rare. Our sample rests on children born in California who have a younger sibling. From 1997 onward, California's Birth Statistical Master Files contain the mother's address at the birth of the child. Address at birth does not allow us to infer where a child grew up. However, for children with younger siblings, we can infer the residential location for those who reside at the address reported on the younger full sibling's birth record. If the two addresses are different-that is, the family has moved-a child's location in the intervening years cannot be pinned down. Yet for those families who have not moved between the two births, we have an uninterrupted observation window on the elder children with information on residence.

To locate the full siblings of our sample, we exact matched mother's date of birth, the father's date of birth, and the first letter of the mother's maiden name from among the 5,900,923 California birth records of children born between 1997 and 2007. These addresses were geocoded to the point level with ArcGIS 9.2 software (ESRI, Redlands, Calif.). This generated 1,284,525 potential sibling groups consisting of 2,830,148 children. Among these sibling groups, 533,244 of the eldest children were born at the same address as that of their next full sibling. A person-year data set was constructed for all these children who had no change in address.

The data set was time censored at the birth of the next sibling-the time after which residential location cannot be ascertained. In our sample, all autism diagnoses are made between the ages of two and six years for 
children born in 1997 or after. Hence, we defined years in which the child was younger than two and older than six as years when the child was not "at risk," and these children were excluded from the sample. Thus, children born in 2004 and after were too young for an autism diagnosis by 2005 , the last full year for which the diagnostic data were available. Similarly, children whose next sibling was born before they turned one year old were also excluded, as they could not have been diagnosed with autism within the observation window. When the observations with missing data are excluded (26,851 person-years; $4.2 \%)$, the final data set has 304,310 children, or 953,622 person-years from 2000 to 2005.

We also have data on every child in California who was diagnosed with autism and was provided services through the California Department of Developmental Services (DDS). These data identify residence at first diagnosis and severity at first diagnosis. Individuals served by the DDS are evaluated on a yearly basis. If they move from one residential location to another over the course of the study period, we capture those movements. Thus, for all children with autism served by the DDS (estimated to be roughly $85 \%$ of all children with autism in California, or roughly 44,000 individuals), we have precise geocoded addresses (see Croen et al. (2002) ${ }^{15}$ These children are those whose autism diagnosis is considered to create an increased probability of an autism diagnosis for those residing in very close proximity, through the social diffusion of information about autism and autism services via interpersonal networks. For those children who were born after 1991 and could be matched to the birth master files (>80\%), we also have their zip code at time of birth.

We linked the DDS data to the sibling sample described above by probabilistically matching on first, middle, and last name; date of birth; race; zip code at birth; and sex. Potential mismatches were manually verified. The linkage rate was above $80 \%$ for all birth cohorts in this study. The majority of the DDS clients not linked to the birth master files were born outside California. The binary dependent variable was then constructed to indicate whether a child in the sibling sample was first given an autism diagnosis by the DDS during a particular year. The same procedure was used to generate the year during which an MR diagnosis with no known etiology was given. Severity scores at first diagnosis were constructed from the DDS's Client Development Evaluation Reports (CDER) and were age standardized.

\footnotetext{
${ }^{15}$ The estimation was based on a comparison between the DDS data and California's special education database. The case definition of autism in the special education database is unclear and is likely to have included children that do not meet the fullsyndrome criteria (i.e., those who have Asperger's or PPD-NOS). Thus, the $85 \%$ coverage estimate is likely to be conservative.
} 
Statistical Analysis

Discrete event history analysis was used to investigate whether proximity to a child with autism affects one's likelihood of being subsequently diagnosed with autism (Box-Steffensmeier and Jones 2004). We estimate the likelihood of being diagnosed with autism during year $t$ with the following model:

$$
\ln \left(\frac{p_{i j t}}{1-p_{i j t}}\right)=\alpha+\beta D_{(t-1) i}+\sum \gamma W_{t i k}+\sum \theta X_{i k}+\sum \delta Z_{t j k},
$$

where $p_{i j t}$ equals the probability that child $i$ in school district $j$ will be diagnosed with autism during year $t$, given that he or she has not already been diagnosed with autism. The terms $\alpha, \beta, \gamma, \theta$, and $\delta$ are logistic regression parameters to be estimated.$^{16}$ The term $D_{(t-1) i}$ is child $i$ 's proximity to the nearest child with autism during the previous year $(t-1)$. In our data, $t-1$ spans 1999-2004. The term $W_{t i k}$ is child $i$ 's values on $k$ time-varying attributes during year $t$ that are likely to affect the chance of a diagnosis. The term $X_{i k}$ is child $i$ 's values on $k$ individual-level attributes that are time invariant. The term $Z_{t j k}$ is child $i$ 's values on $k$ timevarying school-district-level factors. The reported confidence intervals are robust to nonindependence due to repeated measures from the same child.

Our key outcome variable is whether a child was diagnosed with autism during a particular year (year $t$ ). Information on autism diagnosis was based on data between 1992 and 2005 from the DDS in California. As noted previously, the DDS provides services to the majority of patients with autistic disorder (International Classification of Diseases, 9th Revision, Clinical Modification [ICD-9-CM] code 299.0). Individuals diagnosed with other developmental disorders, including Asperger's disorder, childhood disintegrative disorder, Rett's disorder, and PDD-NOS, are ineligible for services and are therefore not included in this study. There are also individuals who, in the absence of a diagnosis for autism, do not receive services from the DDS. Parents thus have a strong incentive to secure an autism diagnosis in order to best provide resources for their children. As mentioned above, whether a child has full-syndrome autism and the year of diagnosis were determined by probabilistically linking the birth master files to the DDS data.

We then model the odds of an autism diagnosis during year $t$ with the

\footnotetext{
${ }^{16}$ Unbiased estimates were obtained using the Stata program ReLogit, which uses a weighted least-squares correction method (Tomz, King, and Zeng 1999) to overcome the fact that the relative paucity of autism cases compared with noncases leads to an underestimation of cases when a maximum-likelihood estimator is used (King and Zeng 1999).
} 
American Journal of Sociology

proximity to the nearest child with autism during year $t-1$ as the predictor. The one-year lag ensures that the proper causal order is retainedinformation diffusion requires that contact precede the diagnosis. We also ensured, by comparing parental information, that the nearest neighbor identified was not a full or a half sibling. To further ensure that relatives were excluded, children whose nearest neighbors with autism were within zero meters in distance are excluded from the analysis (all distances are Euclidean distances calculated using ArcGIS 9.2). For the categorical analysis that we report, proximity was categorized into six groups $(1-250$ meters, 251-500 meters, 501 meters-1 kilometer, 1.01-2 kilometers, 2.015 kilometers, and over 5 kilometers). The modal group was 501 meters1 kilometer and was chosen as the reference category. The natural logarithm of the raw distance was calculated to serve as a continuous measure. For ease of interpretation, the logged distance was reverse coded before it was entered into a regression (i.e., $0-\ln ($ distance)), so that larger values indicate closer proximity.

We include the following individual- and community-level variables to control for exogenous factors that may increase both the likelihood of autism diagnosis and the proximity to a diagnosed child. Year dummies controlled for the effect of the increasing prevalence of autism. Age dummies controlled for the effect of the duration of a child in the person-year data set, which is censored by the birth of the next sibling. Three-yearolds were chosen as the reference category, as three is the most common age at first diagnosis. We also controlled for the key known sociodemographic risk factors for autism-sex, maternal age, and socioeconomic status (Croen et al. 2002; Reichenberg et al. 2006; King and Bearman $2009 b$ ). Socioeconomic status was measured by mother's education (in years) and by whether prenatal care and the birth were paid for by MediCal (California's health welfare system). To control for the effect of access to health-care resources, we also calculated the distances to the nearest DDS office, pediatrician, and autism advocacy organization. The DDS has 21 regional centers that provide services to residents in different areas in California. Data on the locations of all pediatric practices from 2001 to 2004 were geocoded to the point level. Addresses for autism advocacy organizations were obtained from public registries. ${ }^{17}$ The distances to these

\footnotetext{
${ }^{17}$ We searched the IRS Business Master Files from the National Center for Charitable Statistics (2008) for all organizations that identified "autism" as their primary code under the National Taxonomy of Exempt Entities. To identify less formal organizations, which may not have requested tax-exemption status, we conducted exhaustive Internet searches and conducted an online survey. We surveyed 68 organizations, of which $42 \%$ responded, and asked them to name other autism advocacy organizations they worked with in California. For organizations with local chapters, each chapter was recorded as its own entity.
} 
health-care resources were logged and reverse coded to measure proximity to the respective services. We selected school districts to be our neighborhood-level unit. Compared with other administrative boundaries like zip codes or census tracts, school districts are more relevant to families with young children, shape selection into neighborhoods, and have a stronger impact on the structure of social interactions. The perceived quality of schools is one important factor for parents' decisions about where to raise their children, and economists have shown that properties in a good school district are worth more (e.g., Bogart and Cromwell 1997; Black 1999). As noted earlier, we further tested the relevance of school districts to the structure of social interactions by partitioning our sample into children whose nearest neighbor with autism was from $(a)$ the same and (b) a different school district. If school districts do structure interactions between parents, we should expect a stronger proximity effect associated with a child with autism from the same district than that associated with a child with autism from a different district.

To control for the effect of urbanicity, the density of the zero- to nineyear-old population in each school district in year $t-1$ (1999-2004) was calculated on the basis of the 2000 census and the ESRI Sourcebook data (ESRI 2002-4). ${ }^{18}$ The ESRI annual sourcebooks contain population estimates for the zero- to nine-year age range projected from the census data (see ESRI [2007] for details). We interpolated and extrapolated the ESRI and 2000 census data for the years in which data were unavailable (1999 and 2001). The age zero to nine population density was logged before it was entered in the model. Logged median income in the school district, also calculated from the census and ESRI data, was used to control for the effect of neighborhood-level resources. In short, known risk factors for autism that are likely to be meaningfully spatially distributed and institutional variables that could be associated with increased ascertainment are controlled for in our models. ${ }^{19}$

It is possible that factors unobserved in our data can lead to residential sorting. If such omitted variables are also associated with the probability of an autism diagnosis, they can cause a spurious relationship between proximity and autism diagnosis. One straightforward solution is to use a

\footnotetext{
${ }^{18}$ The Los Angeles unified school district was further partitioned into eight subdistricts based on the district's local boundaries.

${ }^{19}$ There are other known risk factors for autism—prematurity, breech birth, twin birth, and, for a small subset of cases (less than 10\%-15\%), genetic markers (Durkin et al. 2008). There is no reason to think that these characteristics of the child shape residential choices of parents, and so they are not included in the analyses.
} 
American Journal of Sociology

fixed-effects model. Here, we test such a model at the school district level. ${ }^{20}$ By including fixed effects, we controlled for the effect of self-selection into school districts based on non-time-varying characteristics. Only the data with variation in the outcome variable-school districts with at least one child from the sample diagnosed with autism - could be used in the fixedeffects model. As this analysis is a comparison within school districts, we constrained a child's nearest neighbor with autism to be someone from the same school district, and a separate set of distances were calculated. Subsequently, we observe whether school districts structure interaction by conducting an edge analysis.

As noted previously, if a social diffusion process is operating, we should expect proximity to a child with autism to also lead to a lower likelihood of being diagnosed with sole MR (of unknown etiology). Therefore, we consider whether a child was diagnosed with sole MR during year $t$ as a second outcome variable. The DDS provides services to the majority of people with MR, and the same record-linkage procedure was used to determine the year a child was diagnosed with MR (of unknown etiology) without autism. We excluded cases of MR with a known etiology (e.g., Down syndrome) because the diagnosis would have been unambiguous and the social diffusion process should be irrelevant. We then examine the effect of proximity on an autism-MR diagnosis and expect that the effect is stronger than that on a sole autism diagnosis.

To test the effect of proximity to children with autism on differential diagnosis between autism and MR, we matched the children who were diagnosed with autism in our sample with those who were diagnosed with sole MR and had the same severity of autism symptoms. We then compared the matched groups' mean proximity to other children with autism in the year before their diagnosis. If a social diffusion mechanism is operating and is given the same level of severity, we should expect the group who received an autism diagnosis to have been closer to other children with autism before the diagnosis than the group who received the MR diagnosis.

Furthermore, diagnosis of higher-functioning autism is more likely to depend on access to diagnostic resources and awareness of symptoms. Thus, we expect that proximity to children with autism has a stronger impact on the likelihood of being later diagnosed with higher-functioning autism. We constructed an age-standardized severity score that measures

\footnotetext{
${ }^{20}$ There are problems associated with using a fixed-effects model in this study. The first is that the fixed effect also eliminates at least part of the effect of social interactions taking place within the school district. The second problem is that, conceptually, the social interaction effect we believe to be present should be most stark when we compare districts with and without children with autism, but fixed-effects models exclude those districts with no cases of autism, and hence our estimation is likely quite conservative.
} 
performance in social interaction, communication, and repetitive behaviors. All DDS clients were evaluated for symptoms of autism at intake to assess their eligibility for services. Our severity measure was based on nine items recorded on the CDER diagnostic and evaluation instrument at the time of intake. Items on the social dimension included peer interaction, interaction with nonpeers, friendship formation, friendship maintenance, and participation in social activities. These items were equally weighted and combined to form a scale; Cronbach's alpha ranged from 0.86 for the 1992 birth cohort to 0.85 for the 2000 birth cohort (Bland and Altman 1997). The communication scale was similarly constructed from three items: word usage, receptive language, and expressive language (Cronbach's alpha was 0.84 in 1992 and 0.77 in 2000). A single CDER item measured repetitive and stereotyped behavior. These three dimensions were then equally weighted and combined to form a global score that ranges from 0 to 100, where higher scores mean higher function and lower scores mean more severe autism symptoms. Since function tends to rise with age, particularly on the communication scale, we adjusted scores by transforming them into standard deviation units and mean centering by age when the CDER was completed. Thus, scores measure how severe a child's symptom presentation was at intake compared with those of other children the same age. The same event history model is then used to assess whether the transition rate to autism varies for children assigned to the most severe $20 \%$ and the least severe $20 \%$. We focus our central attention on the tails of the distribution, where we expect to observe the least (most severe) and the greatest (highest functioning) evidence of social influence underlying the spatial diffusion of diagnoses.

As with high-functioning autism overall, symptom presentation is ambiguous among the very young. We expect the proximity effect to be a stronger predictor of early (at age 3) than of older (at ages 4-6) diagnosis. We then look directly at the information diffused. If the proximity effect is indeed due to a diffusion of information, we should observe a similarity between the referral sources. To test this, we compared the referral source of those children diagnosed with autism in our sample with the referral source of their nearest neighbor with autism. Finally, we examine whether the effect of proximity was modulated by the duration of contact by using information on the residential mobility of the children with autism and a supplementary data set of children who had moved between their own birth and their next sibling's birth. 
American Journal of Sociology

\section{RESULTS}

Figure 1 shows that the prevalence of autism increased rapidly over the birth cohorts between 1997 and 2003. Tables 2 and 3 provide descriptive statistics on our sample and the variables. Of the children born in 2000 in this sibling sample, $0.41 \%$ were diagnosed with autism. This is slightly lower than the prevalence rate of 43 per 10,000 among all children born in California in 2000, as reported in figure 1 . The small discrepancy is probably due to the fact that two known risk factors for autism-parental age and, during the period of increasing prevalence, socioeconomic status-are associated with single-child families. The difference in the rates is small, however, suggesting that our sample does not seriously

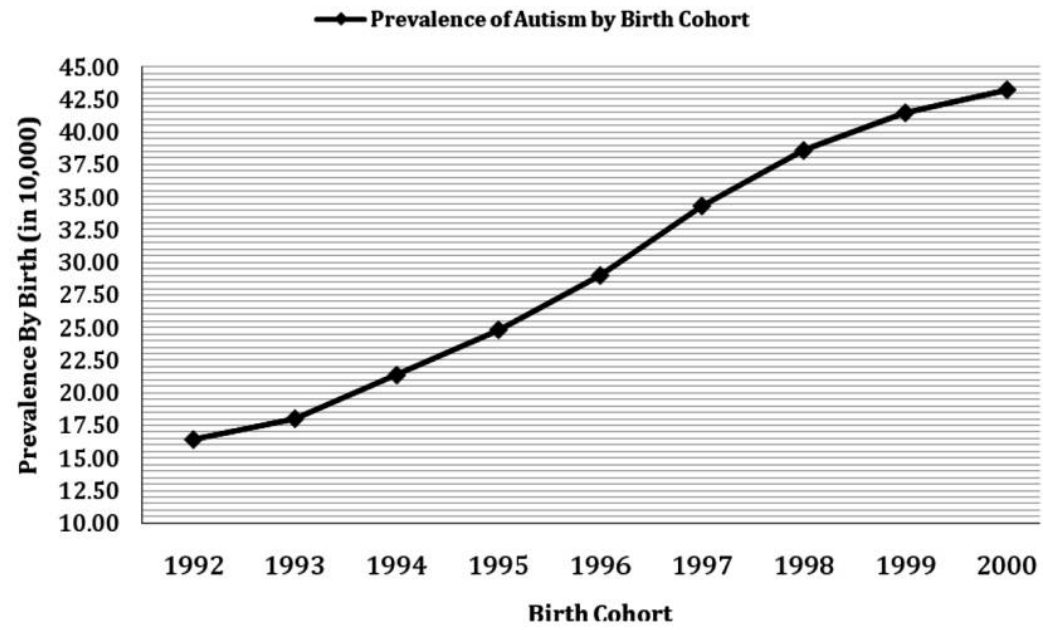

FIG. 1.-Prevalence of autism by birth cohort for children ages three to six in California, 1992-2000.

underestimate prevalence; nevertheless, an only child with autism would not be in our sample, and we can only make inference to children who reside in the same location at birth and diagnosis. We return to these issues when considering limitations.

\section{Social Influence and Spatial Distribution of Autism}

We first consider the effect of logged proximity to the nearest child with autism on the probability of an autism (and MR) diagnosis in the subsequent year. For each condition, we estimated five models. Model 1 controls for the effects of the proximity categories only; model 2 adds the 
TABLE 2

Descriptive Statistics of the SAmple

\begin{tabular}{|c|c|c|c|c|}
\hline & $N$ & $\%$ & Mean & $\mathrm{SD}$ \\
\hline \multicolumn{5}{|l|}{ Birth cohorts: } \\
\hline $1997 \ldots$ & 55,308 & 18.17 & & \\
\hline 1998 & 66,876 & 21.98 & & \\
\hline 1999 & 45,284 & 14.88 & & \\
\hline $2000 \ldots \ldots$ & 44,430 & 14.60 & & \\
\hline $2001 \ldots$ & 39,063 & 12.84 & & \\
\hline 2002 & 32,876 & 10.80 & & \\
\hline $2003 \ldots$ & 20,473 & 6.73 & & \\
\hline Male .......... & 156,042 & 51.28 & & \\
\hline Birth paid by Medi-Cal ........ & 88,871 & 29.20 & & \\
\hline Mother's years of education $\ldots \ldots \ldots \ldots \ldots \ldots \ldots$ & & & 13.0 & 3.4 \\
\hline Mother's age at birth $\ldots \ldots \ldots \ldots \ldots \ldots \ldots \ldots$ & & & 27.9 & 5.4 \\
\hline \multicolumn{5}{|l|}{ Distance to nearest DDS center in 2000, } \\
\hline 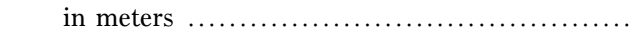 & & & $21,229.0$ & $15,927.2$ \\
\hline Logged distance to nearest DDS center $\ldots \ldots \ldots \ldots \ldots$ & & & 10.0 & .9 \\
\hline \multicolumn{3}{|l|}{ Distance to nearest advocacy organization in 2000 , } & $17,447.8$ & $24,456.7$ \\
\hline \multicolumn{5}{|l|}{ Logged distance to nearest advocacy } \\
\hline organization $\ldots \ldots \ldots \ldots \ldots \ldots \ldots$ & & & 9.2 & 1.1 \\
\hline
\end{tabular}

age and year categories; model 3 adds the individual correlates-gender, mother's age at her child's birth, mother's years of education, and whether birth was paid by Medi-Cal; model 4 adds logged zero- to nine-year-old population density and logged median household income in the school district; and model 5 adds the measures of health-care resources (logged proximity to the nearest DDS office, logged proximity to the nearest pediatrician, and logged proximity to the nearest autism advocacy organization). Full model results are reported in table 4 .

When the effects of all other variables are controlled for, logged proximity has a statistically positive effect on the probability of subsequent autism diagnosis $(\mathrm{OR}=1.26 ; P<.05)$. In figure $2 A$, we graphically represent the effect of logged proximity on subsequent autism diagnosis estimated from the full model. The hollow circles indicate the proportion of children diagnosed with autism during year $t$ in bins of 20,000 personyears sorted by the raw distance to the nearest child with autism. The position on the $X$-axis indicates the average distance of that particular bin. The probability predicted by the logged proximity model follows the data closely. Close proximity (less than one kilometer) is associated with the greatest increase in the probability of being diagnosed with autism.

As the effect of a logged variable cannot be interpreted directly, we also report the results on proximity as a categorical variable. All odds 
American Journal of Sociology

TABLE 3

Descriptive Statistics of the Time-Varying Variables

\begin{tabular}{|c|c|c|c|c|c|}
\hline & $N$ & $\%$ & Mean & $\mathrm{SD}$ & Range \\
\hline \multicolumn{6}{|l|}{ Age: } \\
\hline$\ldots \ldots$ & 374,737 & 39.3 & & & \\
\hline 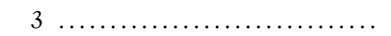 & 321,633 & 33.7 & & & \\
\hline 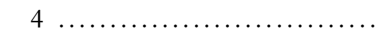 & 158,724 & 16.6 & & & \\
\hline .......... & 69,334 & 7.3 & & & \\
\hline 6 & 29,194 & 3.1 & & & \\
\hline \multicolumn{6}{|l|}{$\begin{array}{l}\text { Distance to the nearest child } \\
\text { with autism in year } t-1 \text { : }\end{array}$} \\
\hline $1-200 \mathrm{~m} \quad \ldots \ldots \ldots \ldots \ldots \ldots$ & 108,402 & 11.4 & & & \\
\hline 201-500 m …............... & 272,107 & 28.5 & & & \\
\hline $501 \mathrm{~m}-1 \mathrm{~km}$ & 295,189 & 31.0 & & & \\
\hline n... & 176,053 & 18.5 & & & \\
\hline 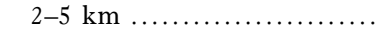 & 63,711 & 6.7 & & & \\
\hline Over $5 \mathrm{~km} \ldots \ldots \ldots \ldots \ldots$ & 38,160 & 4.0 & & & \\
\hline $\begin{array}{l}\text { Distance to the nearest child } \\
\text { with autism, in meters .... }\end{array}$ & & & $1,340.4$ & $3,842.7$ & 1.1 to $154,658.6$ \\
\hline $\begin{array}{l}\text { Logged distance to the nearest } \\
\text { child with autism } \ldots . . . . .\end{array}$ & & & 6.5 & 11.1 & .1 to 12.0 \\
\hline \multicolumn{6}{|l|}{$\begin{array}{l}\text { Age } 0-9 \text { population density in } \\
\text { school district per square }\end{array}$} \\
\hline \multicolumn{6}{|l|}{$\begin{array}{l}\text { Logged age } 0-9 \text { population } \\
\text { density in school }\end{array}$} \\
\hline district $\ldots \ldots \ldots \ldots \ldots \ldots \ldots$ & & & 4.8 & 1.5 & -3.5 to 7.3 \\
\hline $\begin{array}{l}\text { Median household income in } \\
\text { school district, in } \$ \ldots \ldots \ldots\end{array}$ & & & $47,067.6$ & $20,267.7$ & $1,997.4$ to $179,550.2$ \\
\hline
\end{tabular}

Note. $-N=953,622$ person-years.

ratios (ORs) are relative to the reference category of 501 meters- 1 kilometer. These results are graphically reported in figure $2 B$. The $95 \%$ confidence intervals (CIs) from model 1 and model 5 are shown. In figure $2 B$, we can observe that residing in close proximity to a child diagnosed with autism increases one's chance of being diagnosed with autism in the subsequent year. Compared with children who are 501 meters- 1 kilometer away from their nearest neighbor with autism, those in close proximity (1-250 meters) to a child with autism have a $42 \%$ higher chance of being diagnosed with autism in the subsequent year. Proximity of 201-500 meters increases the chance by $22 \%$. In contrast, being farther away from a child with autism reduces the chance of a diagnosis. Although the last three categories were all significantly associated with the decrease $(-21 \%$, $-36 \%$, and $-49 \%$ ), there were no statistically significant differences among these three categories. This is consistent with the results in figure 

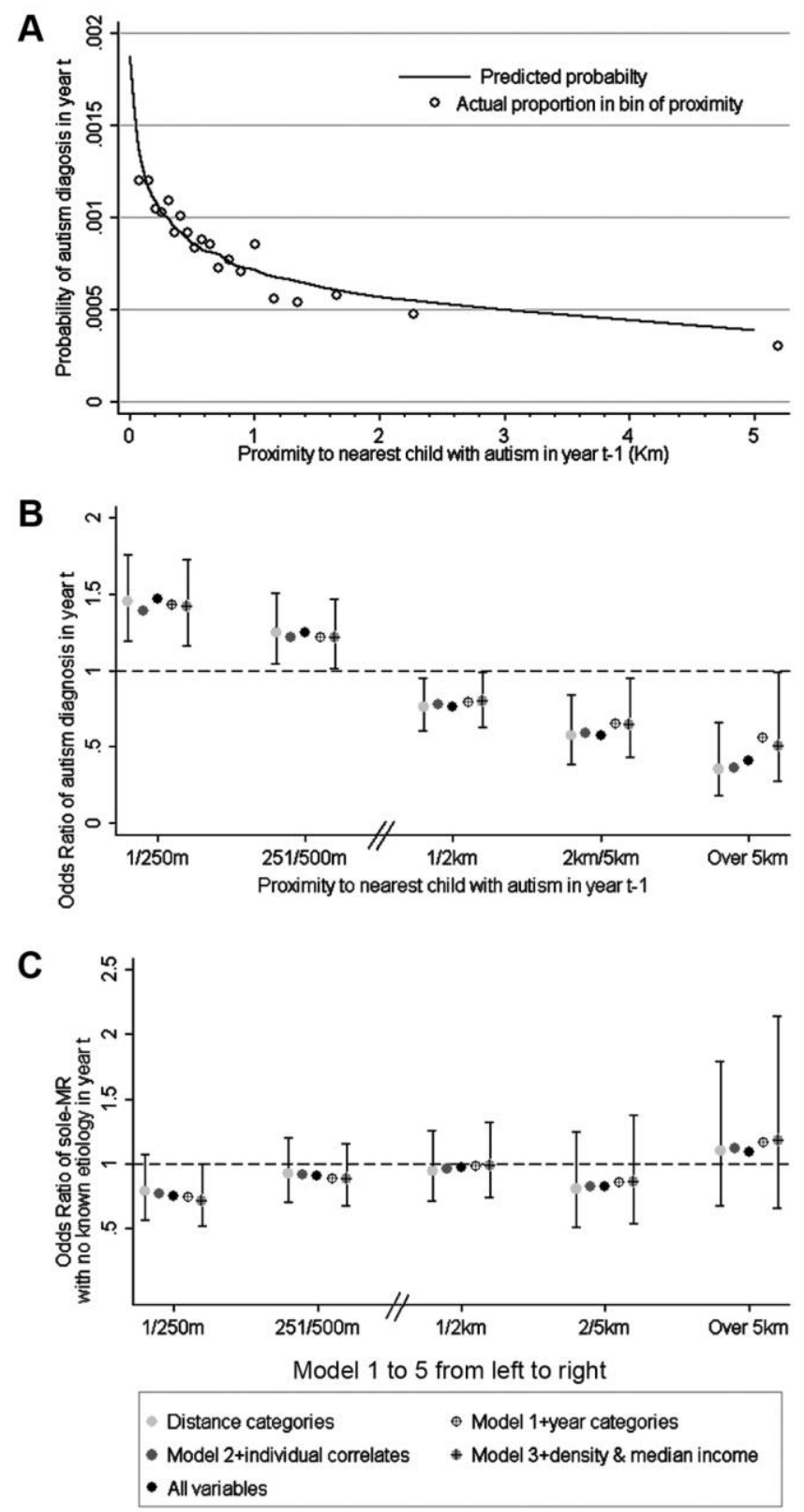

FIG. 2.-Effects of proximity to the nearest child with autism on subsequent diagnosis of autism and MR 


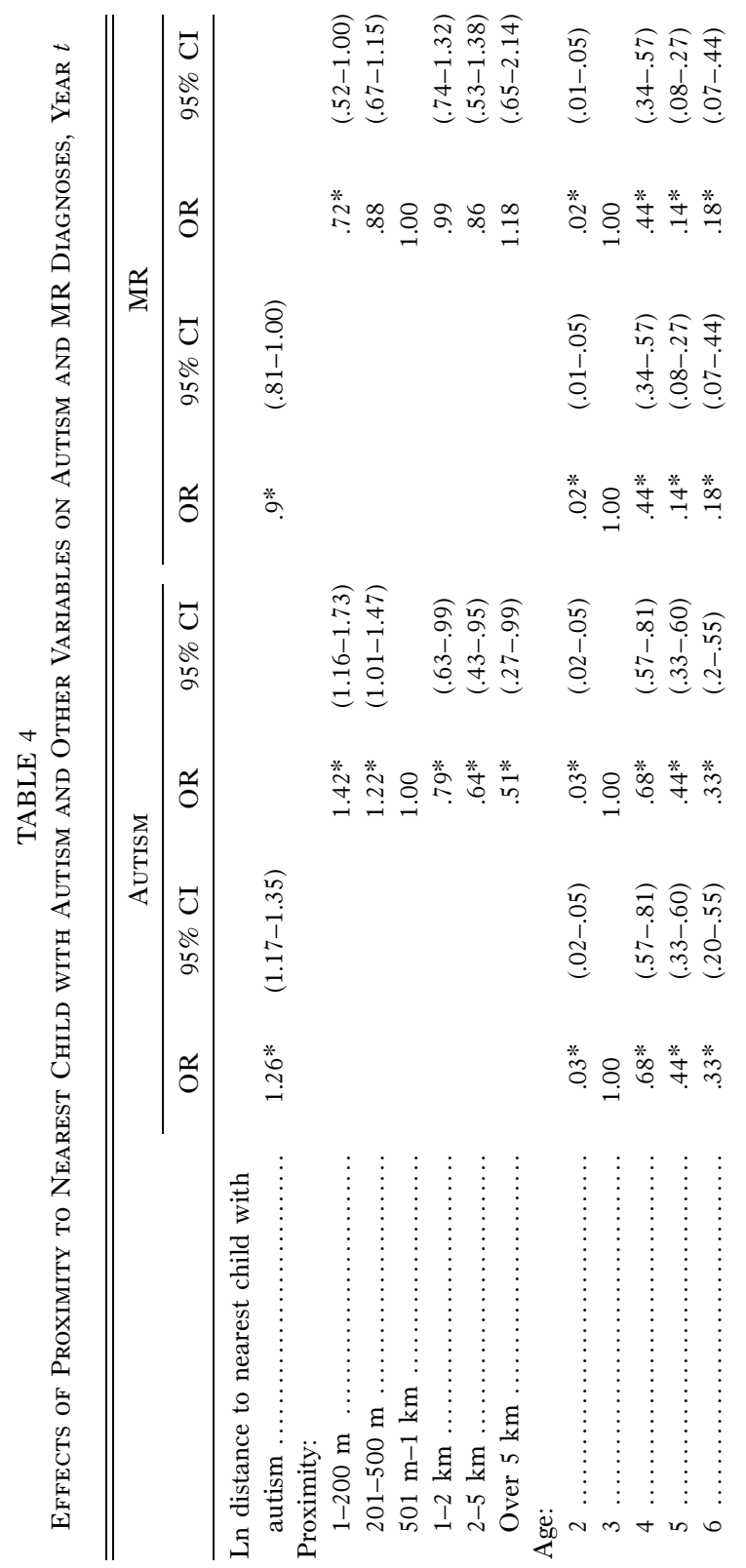

1410 


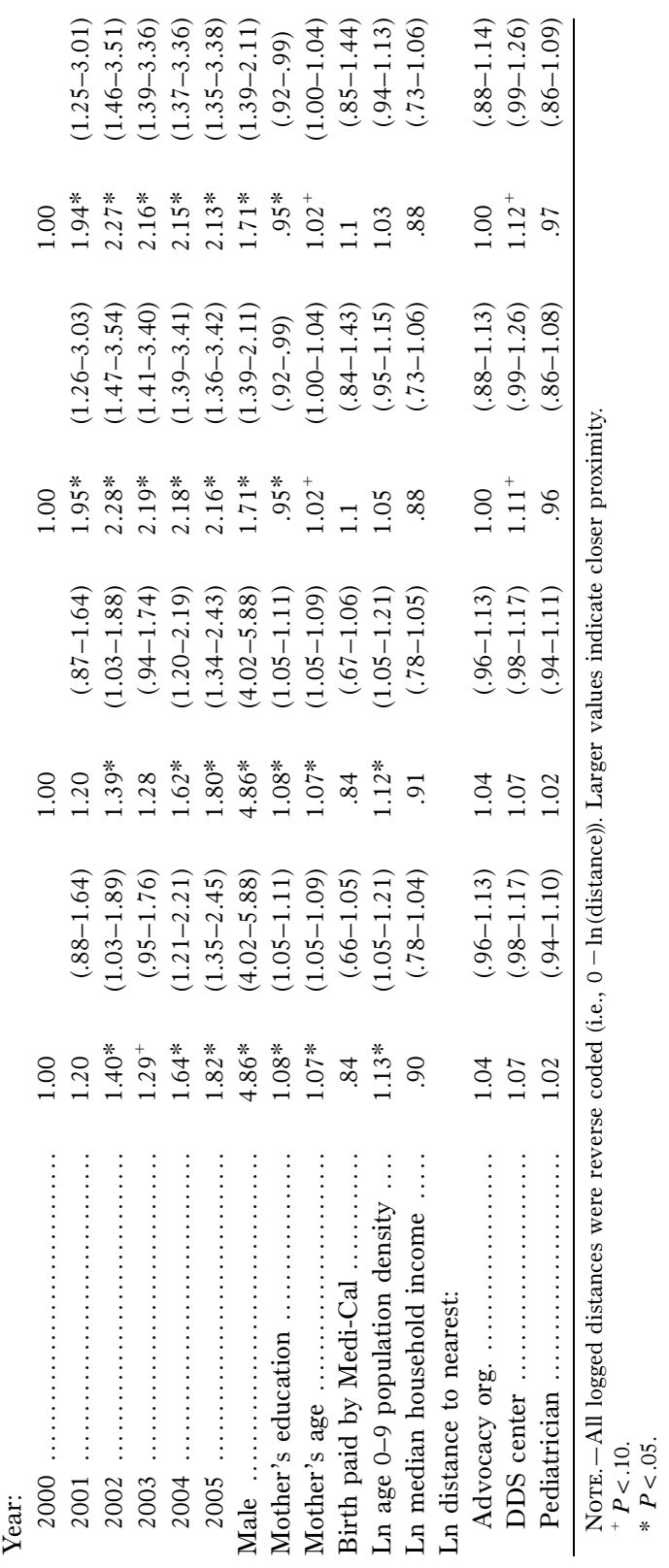

1411 
American Journal of Sociology

$2 A$, which shows that the effect of proximity is strongest within one kilometer, followed by a flat tail.

Figure $2 B$ also graphically shows that the positive effect of proximity is robust after controlling for a range of variables. The individual-level control variables have the expected effect on autism diagnosis as shown in table 4. Specifically, the chance of autism was highest at age 3 and then decreased with age; and the year variables showed an increasing trend, reflecting the rising prevalence of autism. Males are five times more likely to be diagnosed with autism than females are. Mother's age and mother's years of education had a positive effect, and having Medi-Cal pay for the birth had a negative effect. These results are consistent with the positive relationship between socioeconomic status and autism diagnosis reported in the literature. Turning to the community-level variables, we observe that the population density of zero- to nine-year-olds increases the chance of diagnosis. The effect of logged median household income property values is positive but statistically insignificant. Proximity to the nearest DDS office, pediatrician, and autism advocacy organization is also insignificant. Overall, we observe that the proximity effect remains and, in some instances, is amplified in the presence of controls for risk factors at multiple levels of observation.

Because the prevalence of autism is rising, proximity to the nearest child with autism has increased over time simply because there are more children with autism. It is possible that the underlying time trends might have led to a spurious relationship between proximity and the chance of autism diagnosis that cannot be completely eliminated by the year dummies. Specifically, since more children have autism, all children without autism live closer to a child with autism at the end of our observation period than they did at the start. Since autism prevalence is increasing, this could lead us to mistakenly attribute the cause of increased prevalence to proximity. To rule out this possibility, we year mean centered our proximity measure and report the results in table A1 in the appendix. The year-mean-centered proximity has a positive and statistically significant effect on the subsequent diagnosis of autism. The effect can be directly compared with the effect of proximity that is standardized across all years reported in the first column of table A1 (i.e., no adjustment is made for the underlying time trend), as they both have standard deviations as their units. The effect parameter estimate is almost identical. Hence, the effect of proximity on subsequent diagnosis is not an artifact of time.

Another potential confounder is population density. Separate models fitted to areas with high (top 50\%) and low (bottom 50\%) population density are shown in table A2, and the effect of proximity is significant in both models, indicating that the effects we observe are robust to urbanicity. This finding suggests that, unless a toxicant responsible for au- 
tism is equally present in rural and urban areas, the environmental argument is not supported by the evidence at hand. Table A3 reports the results of the fixed-effects model. The fixed effect and the time-varying population density control for all variability in population density between school districts. It shows that the effect of logged proximity remains positive $(P=.06)$. Because the fixed-effects model also controls for the variability in local toxicity and unobserved non-time-varying factors associated with self-selection into school districts, it suggests that the proximity effect is unlikely to be the result of localized toxicants and residential sorting.

\section{Social Influence and Spatial Distribution of MR and Autism-MR}

In figure $2 C$, we consider the impact of residence on subsequent diagnosis of MR. Full model results are reported in table 4. As predicted, the effect of proximity runs in the opposite direction for MR diagnosis. Compared with children 501 meters to one kilometer away from the nearest child with autism, close proximity $(1-250 \mathrm{~m})$ significantly reduces the chance of being diagnosed with MR in the subsequent year $(-28 \% ; P=.05)$. No statistically significant differences in the likelihood are observed for the other distance categories, suggesting that negative social influence operates strongly at very local scales.

If social influence is operating on the autism-MR border, the reduction in sole MR diagnosis associated with proximity should be accompanied by an increased probability of autism-MR diagnoses. Table A4 reports the effect of logged proximity on subsequent autism-MR diagnosis. As predicted, proximity is strongly predictive; the odds ratio associated with a one-unit increase in logged proximity is $1.39(P=.05)$, as compared to the odds ratio of 1.26 for all autism cases (table 4).

The effect of social influence on the differential diagnosis of autism is clearly illustrated when we compare children who received different diagnoses with the same level of severity of autism symptoms. In our data, the range of autism symptoms in children with solely an MR diagnosis enveloped that of children diagnosed with autism. This allows us to construct samples of children with similar severity for autism symptoms but who were diagnosed with MR (of unknown etiology). Propensity score matching was used to generate matched pairs with an almost identical functioning score (within $0.1 \mathrm{SD}$ of the propensity score). There was a match to all children with autism. We then compared the mean distance to the nearest child with autism in the year before diagnosis between the two groups. Given the same level of autism severity, the group who received an autism diagnosis resided 574.6 meters closer to the nearest 
neighbor with autism before diagnosis than did those who received a sole MR diagnosis $(t=-2.36 ; P<.05)$.

Specifically, proximity to a child with autism should have a particularly strong influence on comorbid cases, as they clearly locate on the autismMR border. We thus compared the mean proximity between those who received a sole MR diagnosis and those who received a comorbid autismMR diagnosis, again matched on autism severity. Those who received an autism-MR diagnosis were 806 meters closer to the nearest neighbor with autism before diagnosis than were those who received a sole MR diagnosis $(t=-2.06 ; P<.05) .{ }^{21}$ The difference in proximity is similar to the median distance to the nearest local park in our sample.

In other words, among two children with the same expression of symptoms, the one closer to another child with autism was more likely to be diagnosed with autism or autism-MR, while the other was more likely to be diagnosed with sole MR. This result is consistent with the idea that there is significant social influence on the differential diagnosis between MR and autism.

\section{Social Influence and Severity of Autism Symptoms}

We now consider the impact of social influence on high-functioning autism. In figure 3, we report the effect of a one-unit increase in logged proximity on low-functioning (lowest 20\%) to high-functioning (highest $20 \%$ ) autism. The full model results are reported in table 5. Figure 3 shows that proximity has a stronger effect on high-functioning autism than on severe autism. While the effect of proximity has a strong effect on the odds of a child being diagnosed with high-functioning autism $(40 \%$ for a one-unit decrease in logged distance for the highest-functioning 20\%), it has a weaker impact for the most severe cases $(16 \%$ for a one-unit decrease in logged distance for the most severe 20\%). This is consistent with our expectation that the social diffusion process is operating particularly strongly at the high-functioning border.

As with the observation of a stronger proximity effect on high-functioning autism than on low-functioning autism, we expect the proximity effect to differ by age of diagnosis since symptom presentation is more ambiguous for young children and parental knowledge is of greater importance for early diagnosis. As children age, institutional ascertainment mechanisms-for example, the school system-render parental resources less important. Table A5 shows that this is the case: a one-unit increase in logged proximity is associated with a $31 \%$ increase in the odds of being

${ }^{21}$ Adding the remaining individual-level variables to the propensity score matching yields a significant difference of 415.5 meters $(t=-2.53 ; P<.05)$. 


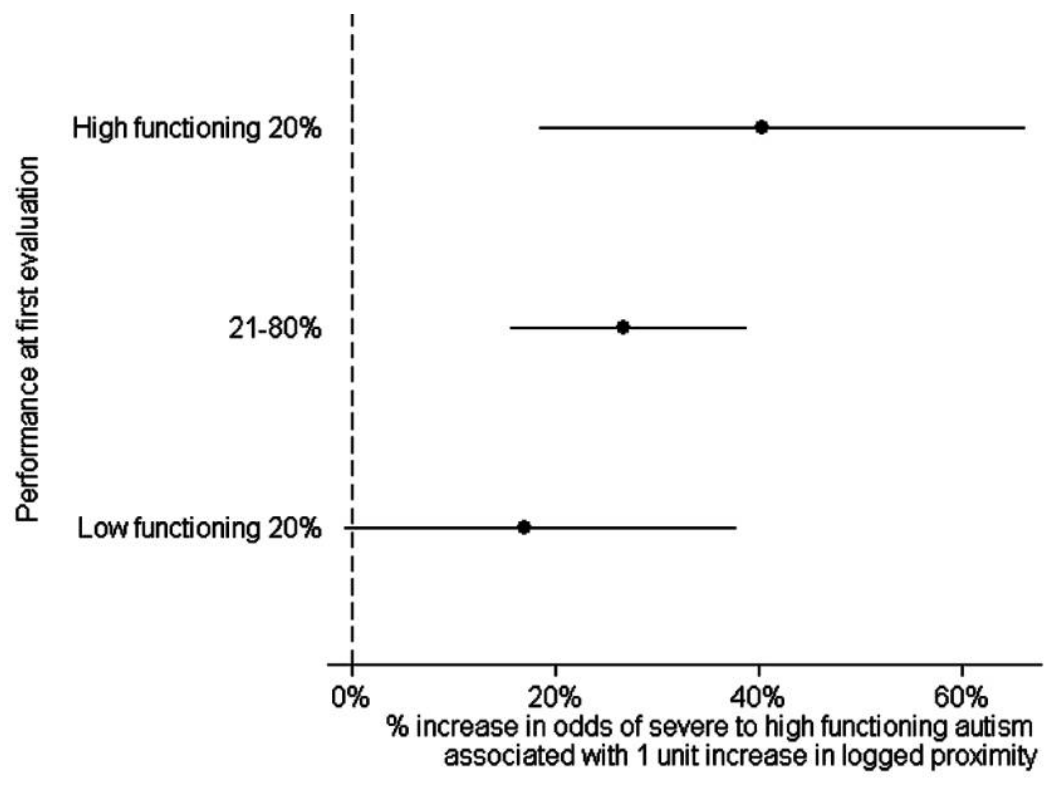

FIG. 3.-Effect of logged proximity on severe to less severe autism

diagnosed with autism at age three; its effect drops to $15 \%$ if the diagnosis was made after age three.

Homophily on Mode of Referral

If information diffusing from the nearest neighbor with autism contributes to subsequent diagnosis, one should expect similarity in the mode of referral to the DDS between children diagnosed with autism and their nearest neighbor with autism. The DDS reports the mode of referral for only a very small proportion of its caseload. While there are no obvious selection issues, the small number of observations suggests that caution should be exercised in drawing inferences. This caveat aside, table 6 reports the mode of referral of the children diagnosed with autism in our sample and that of their nearest neighbor with autism. Strong homophily is found in referral mode, as revealed by the positive relationships on the main diagonal $\left(x^{2}=24.00 ; \mathrm{df}=9 ; P=.004\right)$. Since DDS regional centers could be associated with differential outreach (and hence ascertainment), we control for center catchment areas and observe that the finding is robust. 
TABLE 5

Effect of Logged Proximity to Nearest Child with Autism on Severe AND Less Severe Autism

\begin{tabular}{|c|c|c|c|c|c|c|}
\hline & \multicolumn{2}{|c|}{$\begin{array}{c}\text { Low- } \\
\text { FunCTIONING } \\
20 \%\end{array}$} & \multicolumn{2}{|c|}{$21 \%-80 \%$} & \multicolumn{2}{|c|}{$\begin{array}{c}\text { HIGH- } \\
\text { FunCTIONING } \\
20 \%\end{array}$} \\
\hline & OR & $95 \% \mathrm{CI}$ & OR & $95 \% \mathrm{CI}$ & OR & $95 \% \mathrm{CI}$ \\
\hline \multicolumn{7}{|l|}{$\begin{array}{l}\text { Logged distance to nearest } \\
\text { child with autism }\end{array}$} \\
\hline \multicolumn{7}{|l|}{ Age: } \\
\hline 2 & $.04 *$ & $(.01-.11)$ & $.03 *$ & $(.02-.05)$ & $.05 *$ & $(.02-.12)$ \\
\hline 3 & 1.00 & & 1.00 & & 1.00 & \\
\hline 4 & .76 & $(.52-1.11)$ & $.63^{*}$ & $(.5-.79)$ & .77 & $(.53-1.12)$ \\
\hline 5 & .62 & $(.35-1.10)$ & $.37 *$ & $(.24-.55)$ & $.54^{+}$ & $(.29-1.01)$ \\
\hline 6 & $.34^{+}$ & $(.11-1.07)$ & $.41^{*}$ & $(.22-.76)$ & .41 & $(.13-1.31)$ \\
\hline \multicolumn{7}{|l|}{ Year: } \\
\hline 2000 & 1.00 & & 1.00 & & 1.00 & \\
\hline 2001 & 1.06 & $(.51-2.19)$ & 1.15 & $(.78-1.71)$ & 1.52 & $(.71-3.22)$ \\
\hline 2002 & 1.12 & $(.54-2.32)$ & $1.39^{+}$ & $(.95-2.02)$ & 1.71 & $(.83-3.55)$ \\
\hline 2003 & 1.29 & $(.64-2.59)$ & 1.25 & $(.85-1.84)$ & 1.35 & $(.64-2.85)$ \\
\hline 2004 & 1.67 & $(.86-3.24)$ & $1.50 *$ & $(1.03-2.2)$ & $2.09 *$ & $=(1.02-4.28)$ \\
\hline 2005 & $2.38^{*}$ & $(1.23-4.62)$ & $1.54^{*}$ & $-2.25)$ & $2.05^{+}$ & $(.98-4.29)$ \\
\hline Male & $3.97 *$ & $(2.66-5.91)$ & $5.11^{*}$ & $(3.98-6.56)$ & $5.16^{*}$ & $(3.34-7.96)$ \\
\hline $\begin{array}{l}\text { Mother's years of } \\
\text { education } \ldots \ldots . . .\end{array}$ & 1.04 & 9) & $1.10^{*}$ & $(1.0$ & $1.06^{+}$ & $(1.0$ \\
\hline Mother' & $1.06^{*}$ & $(1.03$ & $1.06^{*}$ & (1.04- & $1.10^{*}$ & $(1.07-1.14)$ \\
\hline Birth paid by Medi-Cal & .84 & $(.52-1.35)$ & .94 & $(.7-1.26)$ & $.51 *$ & $(.28-.94)$ \\
\hline $\begin{array}{c}\text { Logged age } 0-9 \text { population } \\
\text { density } \ldots \ldots \ldots \ldots \ldots\end{array}$ & $1.19^{*}$ & $(1.02-1.39)$ & $1.12 *$ & $(1.02-1.22)$ & 1.10 & $(.93-1.32)$ \\
\hline $\begin{array}{l}\text { Logged median household } \\
\text { income } \ldots \ldots \ldots \ldots \ldots .\end{array}$ & .81 & $(.59-1.12)$ & .89 & $(.73-1.08)$ & 1.03 & $(.77-1.37)$ \\
\hline $\begin{array}{l}\text { Logged distance to nearest } \\
\text { advocacy organization } \\
\text { (reverse coded) }\end{array}$ & 1.00 & $(.84-1.20)$ & 1.07 & $(.96-1.19)$ & .99 & $(.82-1.19)$ \\
\hline $\begin{array}{l}\text { Logged distance to nearest } \\
\text { DDS center (reverse } \\
\text { coded) }\end{array}$ & 1.08 & $(.87-1.33)$ & 1.02 & $(.92-1.14)$ & $1.21^{+}$ & $(.96-1.52)$ \\
\hline $\begin{array}{l}\text { Logged distance to nearest } \\
\text { pediatrician (reverse } \\
\text { coded) }\end{array}$ & $1.19^{+}$ & $(1.00-1.42)$ & .99 & $(.89-1.1)$ & .96 & $(.8-1.15)$ \\
\hline
\end{tabular}

Note. - All logged distances were reverse coded (i.e., $0-\ln ($ distance)). Larger values indicate closer proximity.

${ }^{+} P<.10$.

$* P<.05$. 
Social Influence and Autism

TABLE 6

Homophily of Mode of Referral of Nearest Child with Autism in Year $t-1$

\begin{tabular}{lccccc}
\hline \hline & Self/Family & Physician/Hospital & School & Others & Total \\
\hline Self/family .......... & $11.6(4.4)$ & $6.2(-2.2)$ & $2.4(-2.3)$ & $4.3(-.1)$ & 24.6 \\
Physician/hospital ... & $11.6(-2.1)$ & $19.2(1.7)$ & $10.0(1.1)$ & $8.1(-.7)$ & 48.9 \\
School .............. & $2.4(-1.3)$ & $4.3(.2)$ & $3.0(1.2)$ & $2.2(.0)$ & 11.9 \\
Others .............. & $3.2(-1.1)$ & $5.1(.0)$ & $2.7(.0)$ & $3.5(1.2)$ & 14.6 \\
Total .............. & 28.9 & 34.9 & 18.1 & 18.1 & 100 \\
\hline
\end{tabular}

NotE. - Values are given as total percentages, with adjusted residuals in parentheses. A positive adjusted residual indicates that the observed count is greater than the expected count, and vice versa. $N=370$ pairs; $\chi^{2}=23.9984, \mathrm{df}=9$, prob $=0.004$.

Influence within and across School District Boundaries

It is possible to capture the salience of school districts for structuring interaction by exploiting the fact that some people live on the edge of a district. $^{22}$ In a model controlling for all other individual- and school-level district variables, we first consider the effect of distance for families residing in the same school district by asking whether children living less than 500 meters from a child with autism, compared with those children whose nearest neighbor with autism was 501 meters to one kilometer away, are substantially more likely to be diagnosed with autism in the subsequent year. This turns out to be the case, as can be seen in table 7 $(\mathrm{OR}=1.36 ; P=.001)$. In contrast, compared with the same reference category, a child who lived within 500 meters of a child with autism from a different school district had no increased risk of being diagnosed with autism in the subsequent year $(\mathrm{OR}=1.03 ; P=.912)$. It makes sense that social influence operates only within meaningful social boundaries; for those families with elder siblings, shared school districts provide both the opportunity and the material for social interaction. In addition, information shared-to the extent to which it is salient for navigating public resources that may be allocated through schools-is more accurate. Because environmental factors such as toxicants should not be affected by school district boundaries, such edge effects provide further support to the social interaction mechanism described in this article. Note as well that a potential competing hypothesis-that the operative mechanism at play is influence flowing through physician referral networks-would be inconsistent with the result we observe since referral systems are typically based on distance or insurance carrier (Beltramini and Sirsi 1992). Neither foundation overlaps with school districts, except to the extent to which

${ }^{22}$ We thank one of the $A J S$ reviewers for suggesting that we try to exploit the edge effect in this study. 
TABLE 7

Effect of Proximity on the Likelihood of Subsequent Autism Diagnosis among Children Whose Nearest Neighbor with Autism Was from (A) the Same or (B) a Different School District

\begin{tabular}{|c|c|c|c|c|}
\hline & \multicolumn{2}{|c|}{$\begin{array}{c}\text { (A) SAME } \\
\text { SCHOOL } \\
\text { DISTRICT } \\
(N=849,992) \\
\end{array}$} & \multicolumn{2}{|c|}{$\begin{array}{l}\text { (B) DIFFERENT } \\
\text { SchOOL District } \\
(N=103,472)\end{array}$} \\
\hline & OR & $95 \%$ CI & OR & $95 \% \mathrm{CI}$ \\
\hline \multicolumn{5}{|l|}{ Proximity categories: } \\
\hline $1-500 \mathrm{~m}$ & $1.36^{*}$ & $(1.14-1.62)$ & 1.03 & $(.58-1.85)$ \\
\hline $501 \mathrm{~m}-1 \mathrm{~km}$. & 1.00 & & 1.00 & \\
\hline $1-2 \mathrm{~km} \ldots \ldots$ & $.76^{*}$ & $(.59-.98)$ & .79 & $(.45-1.38)$ \\
\hline $2-5 \mathrm{~km} \ldots$ & .66 & $(.42-1.04)$ & $.39 *$ & $(.16-.94)$ \\
\hline Over $5 \mathrm{~km}$ & .33 & $(.08-1.34)$ & $.31 *$ & $(.12-.83)$ \\
\hline \multicolumn{5}{|l|}{ Age: } \\
\hline 2 & $.03 *$ & $(.02-.05)$ & $.07 *$ & $(.02-.18)$ \\
\hline 3 & 1.00 & & 1.00 & \\
\hline 4 & $.66 *$ & $(.55-.80)$ & .83 & $(.50-1.38)$ \\
\hline 5 & $.41^{*}$ & $(.30-.57)$ & .68 & $(.30-1.53)$ \\
\hline 6 & $.33^{*}$ & $(.19-.56)$ & .24 & $(.03-1.76)$ \\
\hline \multicolumn{5}{|l|}{ Year: } \\
\hline 2000 & 1.00 & & 1.00 & \\
\hline 2001 & 1.14 & $(.81-1.60)$ & 1.58 & $(.68-3.67)$ \\
\hline 2002 & $1.42 *$ & $(1.03-1.96)$ & 1.23 & $(.50-3.01)$ \\
\hline 2003 & 1.25 & $(.90-1.73)$ & 1.68 & $(.71-3.97)$ \\
\hline 2004 & $1.65 *$ & $(1.20-2.27)$ & 1.46 & $(.58-3.65)$ \\
\hline 2005 & $1.82 *$ & $(1.33-2.50)$ & 1.76 & $(.70-4.42)$ \\
\hline Male & $4.62 *$ & $(3.79-5.64)$ & $8.06^{*}$ & $(4.03-16.11)$ \\
\hline Mother's years of education & $1.08 *$ & $(1.05-1.11)$ & $1.12 *$ & $(1.03-1.22)$ \\
\hline Mother's age at birth & $1.07 *$ & $(1.05-1.09)$ & $1.07 *$ & $(1.03-1.12)$ \\
\hline Birth paid by Medi-Cal & .83 & $(.65-1.06)$ & .96 & $(.49-1.87)$ \\
\hline Logged age $0-9$ population density ....... & $1.11 *$ & $(1.03-1.19)$ & 1.19 & $(.95-1.49)$ \\
\hline Logged median household income ......... & .91 & $(.78-1.06)$ & .92 & $(.60-1.41)$ \\
\hline \multicolumn{5}{|l|}{ Logged distance to nearest advocacy } \\
\hline organization (reverse coded) & 1.03 & $(.94-1.12)$ & 1.17 & $(.91-1.51)$ \\
\hline $\begin{array}{l}\text { Logged distance to nearest DDS center } \\
\quad(\text { reverse coded) }\end{array}$ & 108 & (98-1.19) & 106 & \\
\hline $\begin{array}{l}\text { Logged distance to nearest pediatrician } \\
\text { (reverse coded) }\end{array}$ & & & & \\
\hline$(\mathrm{r}$ & 1.01 & $(.93-1.10)$ & 1.10 & $(.87-1.39)$ \\
\hline
\end{tabular}

NoTE. - All logged distances were reverse coded (i.e., $0-\ln ($ distance)). Larger values indicate closer proximity. Fifty-two percent of group A and $41 \%$ of group B lived in the high-populationdensity (top 50\%) school districts.

$* P<.05$. 
the physicians' practice is built from parent referrals arising from parents' social networks bounded by school district.

\section{Stayers and Movers}

We first consider situations in which the focal child-the one at risk for an autism diagnosis-is a stayer and the nearest neighbor with autism is a mover. Our analytical strategy so far has treated potential exposure in each year as independent. If the proximity effect we observe is caused by social interaction, it follows that prolonged and repeated interactions are likely to be associated with a higher increase in the likelihood of subsequent autism diagnosis. In contrast, if a shared toxicological environment induced the proximity effect, it follows that as long as both children were exposed to the same environmental hazard-especially in utero or in the early stages of development - the length of time parents could potentially interact with each other would not matter. More prosaically, it ought to be the case-if the social influence mechanism is operating - that children who lived near the same neighbor with autism in consecutive years would have a higher chance of being diagnosed with autism than would those children who lived near a neighbor with autism who subsequently moved away. In contrast, the environmental toxicant argument predicts that no differences should be observed in these two groups of children. To test these two alternatives, we examine the effect of two-year lagged proximity on autism diagnosis in groups of children who were (1) the same distance to a child with autism in both years, (2) a shorter distance in year $t-1$ than in year $t-2$, and (3) a greater distance in year $t-1$ than in year $t-2$.

As shown in figure 4, residing in close proximity to a child with autism within the past two years has no effect on subsequent autism risk if the neighboring family with autism moved away. In contrast, residing in very close proximity (less than 250 meters) has a statistically significant effect when the nearest neighbor with autism did not move away. The significant positive effect is also observed in the group who had a shorter distance to a child with autism in year $t-1$ than in year $t-2$. This group of children consists of those whose nearest neighbor with autism had moved closer, those who had a new neighbor with autism move into their close proximity, or those who had a neighbor in closer proximity receive an autism diagnosis in year $t-1 .^{23}$

\footnotetext{
${ }^{23}$ It is also the case that more recent proximity has a stronger effect than temporally distal proximity. This result is consistent with social influence and inconsistent with a toxicant or virus, since the effect of the toxicant and/or virus should be stronger in utero or in early development-life stages temporally more distal from diagnosis.
} 


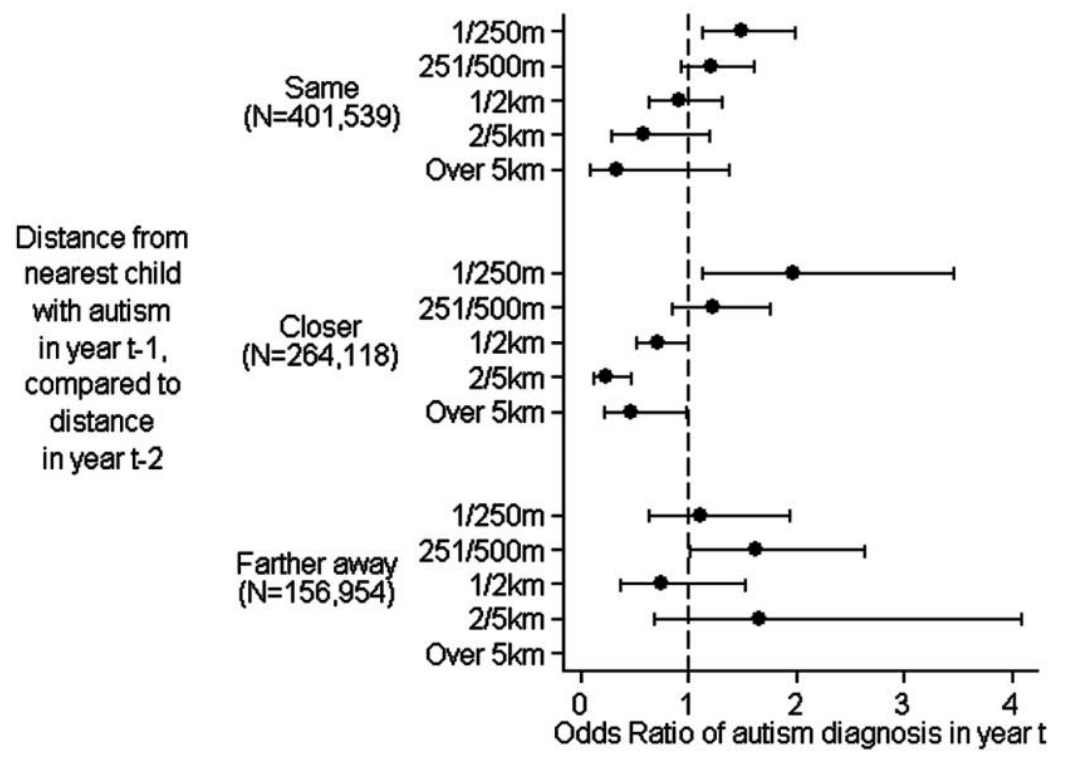

FIG. 4.-Effect of two-year lagged proximity on autism diagnosis in year $t$ by whether the child was (1) the same distance to the nearest child with autism in the two consecutive years, (2) a shorter distance to the nearest child with autism in year $t-1$ than in year $t-2$, and (3) a longer distance to the nearest child with autism in year $t-1$ than in year $t-2$.

We now turn to considering situations in which the focal child-the child at risk for an autism diagnosis-is a mover. To study this context, for children who had different addresses at birth and at their next sibling's birth, we built a cross-sectional data set for the year in which the next sibling was born. ${ }^{24}$ Children who were diagnosed with autism before or in the year in which their next sibling was born and those out of the twoto six-year-old age range were excluded from the analysis. This leaves a total of 336,608 children with a mean age of 3.7 years who had moved from their location at birth to a new location before they could have received an autism diagnosis. For this population, we fitted a logistic regression model to estimate the probability of receiving an autism diagnosis in the years after their next sibling's birth, up to 2006. The key independent variables are continuous and categorical proximity to a neighbor with autism in the year of their next sibling's birth. We further partitioned the mover sample into two groups based on the distance they moved, defining as short-distance movers those whose families moved less

${ }^{24}$ We cannot build a longitudinal data set because we cannot be certain when the family moved during the time between the two births. 
than seven kilometers, which is the median of all observed moves. Results of this analysis are reported in table 8 .

Table 8 shows that even for children whose family moved to a location in close proximity to a child with autism, that proximity has a positive effect on their subsequent odds of obtaining an autism diagnosis. The effects were positive and statistically significant in both the continuous and categorical models (first two columns). Further dividing the sample into short-distance and long-distance movers shows that the effect is not due to short-distance moving. As can be seen from the last two columns, children who had moved more than seven kilometers between their birth and their next sibling's birth (and are therefore more likely to have been exposed to a different set of environmental factors than their current neighbors) were still more likely to be diagnosed with autism after living in close proximity to a child with autism.

\section{Estimate of Effect Sizes}

To provide some idea of the relative importance of the social influence mechanism we identify in generating the increasing prevalence of autism, we calculated the population attributable fractions (PAFs) of residing in close proximity and other demographic variables. The PAF is commonly defined as the reduction in incidence if the population had not been exposed to a risk factor (Rockhill, Newman, and Weinberg 1998). ${ }^{25}$ It can be estimated by the formula PAF $=p c(R R-1) / R R$, where $p c$ is the percentage of cases exposed to a risk factor and $R R$ is the relative risk ratio estimated from multivariate regression. This formula provides unbiased estimates even when exposures to the risk factors are nonindependent (Steenland and Armstrong 2006). To obtain the RRs, we fitted the event history model using a log-binominal model (McNutt et al. 2003), and we used a categorical proximity variable (whether the child lived within a 50-meter radius from a child with autism) and categorical variables for mother's education (whether the mother graduated from college, defined as 16 or more years of education) and mother's age at the time of birth (whether $<35$ years). ${ }^{26}$

Table 9 reports the PAFs. According to this model, if none of the pop-

\footnotetext{
${ }^{25}$ Obviously, the counterfactual condition is never observed, and the estimation method ignores endogeneity and complexity in any causal chain of events. That said, PAFs are useful for comparing the effect sizes of different factors under the current model specification.

${ }^{26} \mathrm{We}$ used the log-binominal model for direct RR estimates, although given the rare occurrence of autism $(<10 \%)$, odds ratios are very close approximations. In fact, the estimates from the log-binominal model are almost identical to those from a logistic regression model.
} 
TABLE 8

Effect of Proximity to a Child with Autism on Subsequent Autism Diagnosis for Children Who Moved between Their Birth and the Birth of THEIR NEXT SibLING

\begin{tabular}{|c|c|c|c|c|c|c|c|c|}
\hline & \multicolumn{4}{|c|}{$\begin{array}{l}\text { All Movers } \\
(N=333,608)\end{array}$} & \multicolumn{2}{|c|}{$\begin{array}{c}\text { SHORT- } \\
\text { DistanCE } \\
\text { MOVERS } \\
(N=169,967)\end{array}$} & \multicolumn{2}{|c|}{$\begin{array}{c}\text { LONG- } \\
\text { DiSTANCE } \\
\text { MoverS } \\
(N=163,641)\end{array}$} \\
\hline & OR & $95 \% \mathrm{CI}$ & OR & $95 \% \mathrm{CI}$ & OR & $95 \% \mathrm{CI}$ & OR & $95 \% \mathrm{CI}$ \\
\hline $\begin{array}{l}\text { Logged distance to } \\
\text { nearest child } \\
\text { with autism } \\
\text { (reverse } \\
\text { coded) ........ }\end{array}$ & $1.12 *$ & $(1.06-1.19)$ & & & & & & \\
\hline $\begin{array}{l}\text { Proximity } \\
\text { categories: }\end{array}$ & & & & & & & & \\
\hline $1-500 \mathrm{~m} \ldots$ & & & $1.22 *$ & $(1.07-1.40)$ & $1.22 *$ & $(1.01-1.47)$ & $1.22 *$ & $(1.01-1.48)$ \\
\hline $501 \mathrm{~m}-1 \mathrm{~km} \ldots$ & & & 1.00 & & 1.00 & & 1.00 & \\
\hline $1-2 \mathrm{~km} \ldots \ldots \ldots$ & & & .90 & $(.76-1.08)$ & .82 & $(.63-1.06)$ & .98 & $(.77-1.23)$ \\
\hline $2-5 \mathrm{~km} \ldots \ldots \ldots$ & & & .85 & $(.65-1.11)$ & .89 & $(.59-1.35)$ & .82 & $(.58-1.16)$ \\
\hline Over $5 \mathrm{~km} \ldots \ldots$ & & & .86 & $(.59-1.26)$ & .80 & $(.39-1.65)$ & .88 & $(.56-1.38)$ \\
\hline Age: & & & & & & & & \\
\hline $2 \ldots \ldots$ & 1.00 & $(.84-1.19)$ & 1.00 & $(.84-1.19)$ & .94 & $(.73-1.20)$ & 1.06 & $(.84-1.34)$ \\
\hline …ㄴ.? & 1.00 & & 1.00 & & 1.00 & & 1.00 & \\
\hline 4 & .96 & $(.83-1.11)$ & .96 & $(.83-1.11)$ & .91 & $(.74-1.12)$ & 1.01 & $(.83-1.24)$ \\
\hline 5 & $.61^{*}$ & $(.50-.74)$ & $.61 *$ & $(.50-.74)$ & $.66^{*}$ & $(.50-.86)$ & $.57 *$ & $(.43-.75)$ \\
\hline … & $.34 *$ & $(.25-.48)$ & $.34 *$ & $(.25-.48)$ & $.27 *$ & $(.16-.45)$ & $.42 *$ & $(.27-.65)$ \\
\hline Year: & & & & & & & & \\
\hline 2001 & $.82^{+}$ & $(.65-1.03)$ & $.82^{+}$ & $(.65-1.03)$ & .84 & $(.60-1.16)$ & .80 & $(.58-1.11)$ \\
\hline 2002 & 1.03 & $(.82-1.28)$ & 1.02 & $(.82-1.28)$ & .86 & $(.62-1.18)$ & 1.18 & $(.87-1.61)$ \\
\hline 2003 & .88 & $(.70-1.11)$ & .88 & $(.70-1.10)$ & .89 & $(.65-1.23)$ & .86 & $(.62-1.19)$ \\
\hline 2004 & .94 & $(.75-1.17)$ & .93 & $(.74-1.16)$ & 1.02 & $(.74-1.39)$ & .84 & $(.61-1.16)$ \\
\hline 2005 & $.82^{+}$ & $(.66-1.04)$ & $.82^{+}$ & $(.65-1.03)$ & .82 & $(.59-1.14)$ & .81 & $(.59-1.12)$ \\
\hline Male . & $4.90 *$ & $(4.20-5.72)$ & $4.90 *$ & $(4.21-5.72)$ & $4.92 *$ & $(3.95-6.14)$ & $4.89 *$ & $(3.94-6.05)$ \\
\hline $\begin{array}{c}\text { Mother's years of } \\
\text { education ..... } \\
\text { Mother's age at }\end{array}$ & $1.07 *$ & $(1.06-1.08)$ & $1.07 *$ & $(1.06-1.08)$ & $1.06 *$ & $(1.04-1.08)$ & $1.08 *$ & $(1.06-1.09)$ \\
\hline $\begin{array}{l}\text { birth ........... } \\
\text { Birth paid by }\end{array}$ & $1.00 *$ & $(1.00-1.01)$ & $1.00 *$ & $(1.00-1.01)$ & 1.00 & $(1.00-1.01)$ & $1.01 *$ & $(1.00-1.01)$ \\
\hline Medi-Cal .. & $.76^{*}$ & $(.66-.88)$ & $.76^{*}$ & $(.66-.88)$ & $.68^{*}$ & $(.56-.83)$ & .87 & $(.71-1.06)$ \\
\hline $\begin{array}{l}\text { Logged age } 0-9 \\
\text { population } \\
\text { density } \ldots \ldots \ldots\end{array}$ & $1.10 *$ & $(1.05-1.15)$ & & $(1.05-1.15)$ & & $(1.01-1.16)$ & & $(1.04-1.18)$ \\
\hline $\begin{array}{l}\text { Logged median } \\
\text { household } \\
\text { income } \ldots \ldots . .\end{array}$ & .93 & $(.79-1.09)$ & .93 & $(.79-1.10)$ & .93 & $(.73-1.17)$ & .92 & $(.73-1.16)$ \\
\hline
\end{tabular}


Social Influence and Autism

TABLE 9

Population Attributable Fractions (PAFs) of Proximity and SOCIOECONOMIC VARIABLES

\begin{tabular}{|c|c|c|c|c|}
\hline & $\begin{array}{l}\text { Proportion } \\
\text { Population } \\
\text { Exposed }\end{array}$ & $\begin{array}{c}\text { Proportion } \\
\text { Cases } \\
\text { Exposed (pc) }\end{array}$ & $\begin{array}{c}\text { Adjusted } \\
\text { Risk Ratio } \\
\text { (RR) }\end{array}$ & $\begin{array}{l}\text { Adjusted } \\
\text { PAF }\end{array}$ \\
\hline Proximity $1-500 \mathrm{~m} \ldots \ldots \ldots$ & .40 & .52 & 1.44 & .16 \\
\hline $\begin{array}{l}\text { Mother graduated from } \\
\text { college } \ldots \ldots \ldots \ldots \ldots \ldots \ldots\end{array}$ & .32 & .44 & 1.25 & .09 \\
\hline $\begin{array}{l}\text { Mother's age over } 35 \text { at } \\
\text { time of birth } \ldots \ldots \ldots \ldots \ldots\end{array}$ & .10 & .22 & 2.04 & .11 \\
\hline Birth paid by Medi-Cal .... & .30 & .17 & .57 & -.13 \\
\hline
\end{tabular}

NOTE. - RRs were estimated by a log-binominal event history model. Estimates were also adjusted for the effect of age; year; gender; logged proximity to the nearest pediatrician, DDS office, and autism advocacy organization; age 0-9 population density in school district; and median income in school district.

ulation lived in very close proximity to a child with autism-within a 500 -meter radius-there would have been a $16 \%$ reduction in autism incidence. The effect of proximity is greater than the effect of the mother's age at the time of birth. Specifically, if all mothers were younger than 35 at the time of birth, we would observe an $11 \%$ decrease in incidence. Likewise, the effect is greater than parental education (if no mothers have a college degree, we would observe a $9 \%$ reduction in incidence). In contrast, removing the effect of Medi-Cal would have increased incidence by $13 \%$. Obviously, Medi-Cal is not protective for autism: poverty simply means that the likelihood of diagnosis is reduced, and so equalizing all health care—so that everyone had better health care—would be associated with an increase in diagnoses.

The counterfactual logic implied in the PAF allows us to assess the relative importance of a factor, but it is not a prescription for social policy. We cannot return to a time when Daniel Boone would be happy-when all mothers had children before they were 35, when no mothers or fathers went to college, and when everyone had a lot of elbow room. The findings reported in this article are agnostic with respect to the question of whether children with autism are now more likely to be identified or whether children are "overdiagnosed." But they are not agnostic to the question of what accounts for a large component of the increased prevalence of autism. To this question, it is quite clear that social influence plays a significant role, accounting for a greater fraction of the increased prevalence of autism than maternal age, socioeconomic status, and all of the known genetic determinants of autism (to date, no single gene has been associated with more than $1 \%-2 \%$ of all autism cases, although Liu, Zerubavel, and Bearman [2010] find evidence consistent with the idea 
American Journal of Sociology

that de novo mutations associated with increased parental age enhance risk for autism).

\section{DISCUSSION}

One does not "catch" autism from someone else, yet a social diffusion process contributes significantly to the increased prevalence of autism. We observe a strong positive effect of proximity to other children with autism on the subsequent chance of diagnosis, robust to a range of individual- and community-level controls in both urban and less urban areas. In addition, close proximity to a child with autism was inversely associated with the likelihood of subsequent sole MR diagnosis, while it correlated strongly with the chance of autism-MR diagnosis. Proximity also increases the chance of autism rather MR diagnosis given the same level of severity in autism symptoms. Social influence arises strongly for high-functioning cases of autism. The effect of proximity is also more prominent in younger children, when diagnosis is more difficult and parental resources are more important. Children who were diagnosed with autism have a similar mode of referral as that of their nearest neighbor with autism before their diagnosis. All of these findings are consistent with a mechanism of social diffusion of awareness of the symptoms and the benefits of treatment and are inconsistent with competing explanations.

Social influence also accounts for the observed spatial clustering of autism. Such clustering could be caused by local environmental toxicants, the diffusion of a virus, or residential selection, but it is hard to see how a toxicant could cause a reduction in MR diagnoses, operate in all types of communities (urban or rural), and affect most strongly the high-functioning end of the severity distribution. The same is true for a virus. The fixed-effects model we consider rules out residential selection on non-timevarying characteristics as a significant driver of the patterns we observe. Despite the findings from the fixed-effects model, it remains possible, however, that the effect of proximity is spuriously caused by some unobserved factors that are associated specifically with higher-functioning autism and that are nonrandomly distributed within school districts. The most likely candidates are socioeconomic factors. The inclusion of individual- and community-level measures of socioeconomic status, however, was associated with little change in the effect of proximity, and in some instances it amplified the effect we observed.

But if people do not catch autism (which they do not), social diffusion dynamics can affect the chance of a diagnosis. Our finding on the negative effect of proximity to children with autism on subsequent sole MR di- 
agnosis provides a new way to understand the dynamics of diagnostic substitution. Explanations based on self-selection of high-risk parents into neighborhoods, viruses, or environmental toxicity would not predict such findings. One might expect that the availability of health-care resources would positively influence the probability of diagnosis for autism - as additional resources should lead to better recognition of symptoms independent of a social diffusion process (Mandell and Palmer 2005; Palmer et al. 2005). As with variables capturing socioeconomic status, proximity to health-care resources-in contrast to expectation- did not have any noticeable impact on the likelihood of diagnosis. This suggests the importance of spatially localized person-to-person contact in affecting parents' decisions to seek out processional help. This has implications for policies aiming at equalizing access to treatments for all parents and communities.

Attention to the structure of social interaction has greatly enhanced our understanding of the diffusion of contagious diseases from the common cold to sexually transmitted diseases (Barthélemy et al. 2005; Watts et al. 2005; Riley 2007). A growing body of evidence has also documented the importance of the social interaction structure on largely behaviorally driven conditions such as obesity (Christakis and Fowler 2007). The current study illustrates that social structure and the interactions that arise from shared foci can have an enormous impact on a childhood disorder that many believe is largely genetically determined and thereby complements a long tradition of theory and research that has identified the critical role of networks in shaping individual health decisions (Clausen and Yarrow 1955; Pescosolido and Boyer 2010).

This study has limitations. First, our data arise from California. Because the DDS provides services only to children with autism and not to children diagnosed with disorders on the autism spectrum, the importance of an autism diagnosis for parents striving to secure resources for their children is amplified. The steep and sudden cliff creates incentives that may not be present in other contexts, but pressure to do anything to help children is likely widespread and not limited to the California context. As Judith Rapoport of the National Institute of Mental Health told Grinker (2007, p. 131), "I'll call a kid a zebra if it will get him the educational services I think he needs." Still, the structure of service provision in California creates enormous pressure on autism diagnoses in ways that make inference to the national context - with respect to the population attributable fraction-difficult. Our data are also limited to families who have more than one child and are not movers. We can observe that families with multiple children who move within the window of our study are not significantly different from those who do not move, but families with one child are quite different from families with more children. This also means 
that assessing the effect size of the diffusion mechanism is difficult and that inferences can be safely made only for families with multiple children.

Finally, we are unable to completely rule out environment or viruses as causes of the specific spatial patterns we observe. What is possibleand perhaps most likely - is that an initial environmental shock gave rise to a slight increase in autism, inducing the social influence cascade described in this article. If this is the case, then identifying the toxicant responsible will be more difficult, since simple correlation to current caseload may be misleading. For an environmental toxicant or virus to be solely responsible for the results we report in this article, it would have to be present at a local scale in all kinds of neighborhoods, from manufacturing centers to agricultural regions, from urban areas to rural communities, and in suburbs both close to the sea and deep inland; be causally related to autism only for the least severely affected individuals and be positively related to fewer (not more) diagnoses of MR; lead to the same mode of referral to the DDS; work for younger kids more than older kids; and operate at the most microscopic levels of interaction. There surely could be such a virus or such a toxicant, but the parsimonious explanation involves neither and points strongly to the diffusion of information operating at a local scale for cases where diagnosis is most difficult and for individuals whose children would most benefit from a diagnosis of autism versus MR, thus inducing a decline in MR diagnoses. In contrast, social influence makes sense of the increased prevalence, declining age of diagnosis, and spatial clustering of autism. 


\section{APPENDIX}

TABLE A1

Effect of Year-Mean-Centered and Study Period-Mean-Centered Logged Proximity to Nearest Child with Autism on Subsequent Autism Diagnosis

\begin{tabular}{|c|c|c|c|c|}
\hline & \multicolumn{2}{|c|}{$\begin{array}{l}\text { YEAR MEAN } \\
\text { CENTERED }\end{array}$} & \multicolumn{2}{|c|}{$\begin{array}{c}\text { Study Period } \\
\text { MEAN } \\
\text { CENTEREd }\end{array}$} \\
\hline & OR & $95 \% \mathrm{CI}$ & OR & $95 \% \mathrm{CI}$ \\
\hline $\begin{array}{l}\text { Logged distance to nearest child with autism } \\
\quad(\text { reverse coded }) \\
\quad \ldots \ldots \ldots \ldots \ldots \ldots \ldots \ldots \ldots\end{array}$ & $1.27 *$ & $(1.18-1.37)$ & $1.28^{*}$ & $(1.18-1.38)$ \\
\hline \multicolumn{5}{|l|}{ Age: } \\
\hline 2 & $.03 *$ & $(.02-.05)$ & $.03 *$ & $(.02-.05)$ \\
\hline 3 & 1.00 & & 1.00 & \\
\hline 4 & $.68^{*}$ & $(.57-.81)$ & $.68^{*}$ & $(.57-.81)$ \\
\hline 5 & $.44^{*}$ & $(.33-.60)$ & $.44^{*}$ & $(.33-.60)$ \\
\hline 6 & $.33^{*}$ & $(.20-.55)$ & $.33^{*}$ & $(.20-.55)$ \\
\hline \multicolumn{5}{|l|}{ Year: } \\
\hline 2000 & 1.00 & & 1.00 & \\
\hline 2001 & 1.24 & $(.90-1.69)$ & 1.20 & $(.88-1.64)$ \\
\hline 2002 & $1.48^{*}$ & $(1.09-2.00)$ & $1.40 *$ & $(1.03-1.89)$ \\
\hline 2003 & $1.40 *$ & $(1.03-1.91)$ & $1.29^{+}$ & $(.95-1.76)$ \\
\hline 2004 & $1.80 *$ & $(1.34-2.43)$ & $1.64 *$ & $(1.21-2.21)$ \\
\hline 2005 & $2.03 *$ & $(1.51-2.73)$ & $1.82 *$ & $(1.35-2.45)$ \\
\hline Male & $4.86^{*}$ & $(4.02-5.88)$ & $4.86^{*}$ & $(4.02-5.88)$ \\
\hline Mother's years of education & $1.08 *$ & $(1.05-1.11)$ & $1.08 *$ & $(1.05-1.11)$ \\
\hline Mother's age at birth $\ldots . \ldots \ldots \ldots . .$. & $1.07 *$ & $(1.05-1.09)$ & $1.07 *$ & $(1.05-1.09)$ \\
\hline Birth paid by Medi-Cal ............... & .84 & $(.66-1.05)$ & .84 & $(.66-1.05)$ \\
\hline Logged age $0-9$ population density $\ldots \ldots \ldots \ldots \ldots \ldots$ & $1.13 *$ & $(1.05-1.21)$ & $1.13^{*}$ & $(1.05-1.21)$ \\
\hline Logged median household income $\ldots \ldots \ldots \ldots \ldots \ldots$ & .90 & $(.78-1.04)$ & .90 & $(.78-1.04)$ \\
\hline $\begin{array}{l}\text { Logged distance to nearest advocacy organization } \\
\quad(\text { reverse coded }) \ldots \ldots \ldots \ldots \ldots \ldots \ldots \ldots \ldots \ldots \ldots \ldots\end{array}$ & 1.04 & $(.96-1.13)$ & 1.04 & $(.96-1.13)$ \\
\hline $\begin{array}{l}\text { Logged distance to nearest DDS center (reverse } \\
\text { coded) } \ldots \ldots \ldots \ldots \ldots \ldots \ldots \ldots \ldots \ldots \ldots \ldots\end{array}$ & 1.07 & $(.98-1.17)$ & 1.07 & $(.98-1.17)$ \\
\hline $\begin{array}{l}\text { Logged distance to nearest pediatrician (reverse } \\
\text { coded) } \ldots \ldots \ldots \ldots \ldots \ldots \ldots \ldots \ldots \ldots \ldots \ldots \ldots \ldots\end{array}$ & 1.02 & $(.94-1.10)$ & 1.02 & $(.94-1.10)$ \\
\hline
\end{tabular}

NotE.-All logged distances were reverse coded (i.e., $0-\ln$ (distance)). Larger values indicate closer proximity.

${ }^{+} P<.10$.

$* P<.05$. 
TABLE A2

Effect of Logged Proximity to Nearest Child with Autism on Subsequent Autism Diagnosis, by Urbanicity

\begin{tabular}{|c|c|c|c|c|}
\hline & \multicolumn{2}{|c|}{$\begin{array}{c}\text { URBAN } \\
(N=480,524)\end{array}$} & \multicolumn{2}{|c|}{$\begin{array}{l}\text { LESS URBAN } \\
(N=472,940)\end{array}$} \\
\hline & OR & $95 \% \mathrm{CI}$ & OR & $95 \% \mathrm{CI}$ \\
\hline \multicolumn{5}{|l|}{ Logged distance to nearest child with autism } \\
\hline \multicolumn{5}{|l|}{ Age: } \\
\hline 2 & $.03 *$ & $(.02-.06)$ & $.03 *$ & $(.02-.07)$ \\
\hline 3 & 1.00 & & 1.00 & \\
\hline 4 & $.63 *$ & $(.50-.80)$ & $.76^{*}$ & $(.58-.98)$ \\
\hline 5 & $.45 *$ & $(.31-.66)$ & $.44 *$ & $(.28-.70)$ \\
\hline 6 & $.43 *$ & $(.24-.77)$ & $.20 *$ & $(.06-.62)$ \\
\hline \multicolumn{5}{|l|}{ Year: } \\
\hline 2000 & 1.00 & & 1.00 & \\
\hline 2001 & $1.49^{+}$ & $(.98-2.26)$ & .90 & $(.55-1.46)$ \\
\hline 2002 & $1.52 *$ & $(1.01-2.29)$ & 1.28 & $(.82-2.01)$ \\
\hline 2003 & $1.43^{+}$ & $(.94-2.18)$ & 1.15 & $(.74-1.81)$ \\
\hline 2004 & $1.69^{*}$ & $(1.12-2.56)$ & $1.56^{*}$ & $(1.01-2.42)$ \\
\hline 2005 & $2.09^{*}$ & $(1.38-3.16)$ & $1.52^{+}$ & $(.98-2.35)$ \\
\hline Male .. & $4.80^{*}$ & $(3.73-6.17)$ & $4.92 *$ & $(3.68-6.58)$ \\
\hline Mother's years of education & $1.09 *$ & $(1.05-1.13)$ & $1.08^{*}$ & $(1.03-1.13)$ \\
\hline Mother's age at birth & $1.08^{*}$ & $(1.05-1.10)$ & $1.06^{*}$ & $(1.04-1.09)$ \\
\hline Birth paid by Medi-Cal & .88 & $(.67-1.16)$ & .70 & $(.46-1.09)$ \\
\hline Logged age $0-9$ population density $\ldots \ldots \ldots \ldots \ldots \ldots$ & $1.28 *$ & $(1.07-1.53)$ & .98 & $(.86-1.13)$ \\
\hline Logged median household income $\ldots \ldots \ldots \ldots \ldots \ldots$ & .96 & $(.72-1.28)$ & .92 & $(.76-1.12)$ \\
\hline $\begin{array}{l}\text { Logged distance to nearest advocacy organization } \\
\quad(\text { reverse coded }) \ldots \ldots \ldots \ldots \ldots \ldots \ldots \ldots \ldots \ldots \ldots\end{array}$ & 1.03 & $(.91-1.17)$ & .99 & $(.87-1.13)$ \\
\hline $\begin{array}{l}\text { Logged distance to nearest DDS center (reverse } \\
\text { coded) } \ldots \ldots \ldots \ldots \ldots \ldots \ldots \ldots \ldots \ldots \ldots \ldots \ldots\end{array}$ & 1.07 & $(.94-1.22)$ & 1.03 & $(.90-1.18)$ \\
\hline $\begin{array}{l}\text { Logged distance to nearest pediatrician (reverse } \\
\text { coded) } \ldots \ldots \ldots \ldots \ldots \ldots \ldots \ldots \ldots \ldots \ldots \ldots \ldots \ldots\end{array}$ & .99 & $(.89-1.10)$ & 1.02 & $(.90-1.16)$ \\
\hline
\end{tabular}

NotE. - All logged distances were reverse coded (i.e., 0 - $\ln$ (distance)). Larger values indicate closer proximity. Urban and less urban samples are defined as those above and below the median age zero to nine population density.

$+P<.10$.

$* P<.05$. 
TABLE A3

Effect of Logged Proximity to Nearest Child on Subsequent Autism Diagnosis, Estimated from Fixed-Effects Model

\begin{tabular}{|c|c|c|}
\hline & OR & $95 \% \mathrm{CI}$ \\
\hline $\begin{array}{l}\text { Logged distance to nearest child with autism (reverse } \\
\text { coded) } \ldots \ldots \ldots \ldots \ldots \ldots \ldots \ldots \ldots \ldots \ldots \ldots \ldots \ldots \ldots \ldots \ldots \ldots \ldots\end{array}$ & $1.09^{+}$ & $(1.00-1.18)$ \\
\hline \multicolumn{3}{|l|}{ Age: } \\
\hline 2 & $.03 *$ & $(.02-.05)$ \\
\hline 3 & 1.00 & \\
\hline 4 & $.67 *$ & $(.56-.80)$ \\
\hline 5 & $.43 *$ & $(.32-.58)$ \\
\hline 6 & $.32 *$ & $(.19-.53)$ \\
\hline \multicolumn{3}{|l|}{ Year: } \\
\hline 2000 & 1.00 & \\
\hline 2001 & 1.24 & $(.90-1.72)$ \\
\hline 2002 & $1.49 *$ & $(1.04-2.14)$ \\
\hline 2003 & $1.40^{+}$ & $(.99-1.98)$ \\
\hline 2004 & $1.68 *$ & $(1.24-2.28)$ \\
\hline 2005 & $1.89^{*}$ & $(1.39-2.57)$ \\
\hline Male ..... & $4.94 *$ & $(4.07-5.99)$ \\
\hline Mother's years of education .. & $1.08 *$ & $(1.04-1.11)$ \\
\hline Mother's age at birth & $1.07 *$ & $(1.05-1.08)$ \\
\hline Birth paid by Medi-Cal & $.82^{+}$ & $(.65-1.03)$ \\
\hline Logged age $0-9$ population density ... & 1.63 & $(.14-19.16)$ \\
\hline Logged median household income ... & 1.28 & $(.44-3.73)$ \\
\hline
\end{tabular}

Note.-One in 371 school districts $(N=168,585)$ was dropped because all outcomes were negative. The remaining number of groups was $236(N=749,571)$. All logged distances were reverse coded (i.e., $0-\ln ($ distance)). Larger values indicate closer proximity.

${ }^{+} P<.10$.

$* P<.05$.

TABLE A4

Effect of Logged Proximity to Nearest Child with Autism on Subsequent Comorbid Autism-MR Diagnosis

\begin{tabular}{|c|c|c|}
\hline & OR & $95 \% \mathrm{CI}$ \\
\hline $\begin{array}{l}\text { Logged distance to nearest child with autism (reverse } \\
\text { coded) } \ldots \ldots \ldots \ldots \ldots \ldots \ldots \ldots \ldots \ldots \ldots \ldots \ldots \ldots \ldots \ldots \ldots \ldots \ldots \ldots\end{array}$ & $1.39 *$ & $(1.01-1.92)$ \\
\hline \multicolumn{3}{|l|}{ Age: } \\
\hline$\ldots$ & $.00^{+}$ & $(.00-.04)$ \\
\hline 3 & 1.00 & \\
\hline$\ldots$ & 1.09 & $(.60-1.99)$ \\
\hline$\ldots$ & 1.77 & $(.56-5.63)$ \\
\hline$\ldots$ & .97 & $(.08-11.61)$ \\
\hline \multicolumn{3}{|l|}{ Year: } \\
\hline 2000 & 1.00 & \\
\hline 2001 & 1.16 & $(.51-2.64)$ \\
\hline $2002 \ldots \ldots \ldots$ & 1.01 & $(.43-2.38)$ \\
\hline
\end{tabular}

1429 


\begin{tabular}{|c|c|c|}
\hline 2003 & .97 & $(.40-2.35)$ \\
\hline 2004 & 1.63 & $(.65-4.11)$ \\
\hline 2005 & $4.14^{*}$ & $(1.44-11.91)$ \\
\hline Male & .75 & $(.40-1.41)$ \\
\hline Mother's years of education & 1.06 & $(.96-1.16)$ \\
\hline Mother's age at birth & $1.05^{+}$ & $(1.00-1.10)$ \\
\hline Birth paid by Medi-Cal & 1.20 & $(.59-2.42)$ \\
\hline Logged age $0-9$ population density . & 1.03 & $(.81-1.32)$ \\
\hline Logged median household income .......... & 1.17 & $(.72-1.90)$ \\
\hline $\begin{array}{l}\text { Logged distance to nearest advocacy organization (reverse } \\
\text { coded) } \ldots \ldots \ldots \ldots \ldots \ldots \ldots \ldots \ldots \ldots \ldots \ldots \ldots \ldots \ldots \ldots \ldots \ldots \ldots \ldots \ldots \ldots \ldots \ldots\end{array}$ & 1.02 & $(.80-1.30)$ \\
\hline Logged distance to nearest DDS center (reverse coded) & .85 & $(.67-1.08)$ \\
\hline Logged distance to nearest pediatrician (reverse coded). & 1.12 & $(.82-1.53)$ \\
\hline
\end{tabular}

Note. - All logged distances were reverse coded (i.e., $0-\ln ($ distance)). Larger values indicate closer proximity.

${ }^{+} P<.10$.
${ }^{*} P<.05$.

TABLE A5

Effect of Logged Proximity to Nearest Child with Autism on Subsequent Autism Diagnosis, by Age of Diagnosis

\begin{tabular}{|c|c|c|c|c|}
\hline & \multicolumn{2}{|c|}{$\begin{array}{c}\text { AgE } 3 \text { AT } \\
\text { Diagnosis }\end{array}$} & \multicolumn{2}{|c|}{$\begin{array}{c}\text { OLDER THAN } \\
\text { AGE } 3 \text { AT } \\
\text { DIAGNOSIS }\end{array}$} \\
\hline & OR & $95 \% \mathrm{CI}$ & OR & $95 \% \mathrm{CI}$ \\
\hline \multicolumn{5}{|l|}{$\begin{array}{l}\text { Logged distance to nearest child with au- } \\
\text { tism }\end{array}$} \\
\hline \multicolumn{5}{|l|}{ Year: } \\
\hline 2000 & 1.00 & & 1.00 & \\
\hline 2001 & 1.12 & $(.80-1.58)$ & & \\
\hline 2002 & 1.28 & $(.92-1.78)$ & 1.05 & $(.68-1.62)$ \\
\hline 2003 & 1.25 & $(.89-1.74)$ & .84 & $(.54-1.30)$ \\
\hline 2004 & $1.72 *$ & $(1.25-2.36)$ & .92 & $(.60-1.41)$ \\
\hline 2005 & $1.86^{*}$ & $(1.35-2.56)$ & .97 & $(.63-1.51)$ \\
\hline Male & $4.72 *$ & $(3.74-5.95)$ & $5.22 *$ & $(3.70-7.39)$ \\
\hline Mother's years of education & $1.09^{*}$ & $(1.05-1.13)$ & $1.07 *$ & $(1.02-1.12)$ \\
\hline Mother's age at birth & $1.07 *$ & $(1.05-1.09)$ & $1.07 *$ & $(1.04-1.10)$ \\
\hline Birth paid by Medi-Cal & .84 & $(.62-1.12)$ & .82 & $(.56-1.19)$ \\
\hline Logged age $0-9$ population density & $1.12 *$ & $(1.03-1.23)$ & $1.14 *$ & $(1.01-1.28)$ \\
\hline Logged median household income & $.85^{+}$ & $(.71-1.02)$ & 1.03 & $(.81-1.31)$ \\
\hline Ln distance to nearest advocacy org. & 1.01 & $(.91-1.12)$ & 1.04 & $(.90-1.21)$ \\
\hline Ln distance to nearest DDS center & 1.06 & $(.95-1.19)$ & 1.12 & $(.94-1.33)$ \\
\hline Ln distance to nearest pediatrician & 1.00 & $(.91-1.11)$ & 1.06 & $(.91-1.23)$ \\
\hline
\end{tabular}

Note. - All logged distances were reverse coded (i.e., $0-\ln ($ distance)). Larger values indicate closer proximity.

${ }^{+} P<.10$.

$* P<.05$. 
Social Influence and Autism

\section{REFERENCES}

$\rightarrow$ Ashwood, Paul, and Judy Van de Water. 2004. "Is Autism an Autoimmune Disease?" Autoimmunity Reviews 3:557-62.

$\rightarrow$ Barthélemy, Marc, Alain Barrat, Romualdo Pastor-Satorras, and Alessandro Vespignani. 2005. "Dynamical Patterns of Epidemic Outbreaks in Complex Heterogeneous Networks." Journal of Theoretical Biology 235:275-88.

$\rightarrow$ Beltramini, Richard R., and Ajay K. Sirsi. 1992. "Informational Influences on Physician Referrals." Journal of Hospital Marketing 6 (2): 101-26.

Bettelheim, Bruno. 1967. The Empty Fortress: Infantile Autism and the Birth of the Self. New York: Free Press.

$\rightarrow$ Black, Sandra E. 1999. "Do Better Schools Matter? Parental Valuation of Elementary Education." Quarterly Journal of Economics 114:577-99.

$\rightarrow$ Bland, J. Martin, and Douglas G. Altman. 1997. "Statistics Notes: Cronbach's Alpha." BMJ 314:572.

Bogart, William T., and Brian A. Cromwell. 1997. "How Much More Is a Good School District Worth?” National Tax Journal 50:215-32.

Box-Steffensmeier, Janet, and Bradford Jones. 2004. Event History Modeling: A Guide for Social Scientists. Cambridge: Cambridge University Press.

Braddock, David. 2007. "Washington Rises: Public Financial Support for Intellectual Disability in the United States, 1955-2004." Mental Retardation and Developmental Disabilities Research Reviews 13:169-77.

California Department of Developmental Services. 2003. "Autistic Spectrum Disorders: Changes in the California Caseload; An Update: 1999 through 2002." California Health and Human Services Agency, California Department of Developmental Services, Sacramento.

$\rightarrow$ Campbell, Karen, and Barrett Lee. 1992. "Sources of Personal Neighborhood Networks: Social Integration, Need or Time?" Social Forces 70:1077-1100.

CDC (Centers for Disease Control and Prevention). 2007. "Prevalence of Autism Spectrum Disorders-Autism and Developmental Disabilities Monitoring Network, Six Sites, United States, 2000." Morbidity and Mortality Weekly Report: Surveillance Summaries 56 (1): 1-11.

$\rightarrow$ Charman, Tony, Andrew Pickles, Susie Chandler, Lorna Wing, Susan Bryson, Emily Simonoff, Tom Loucas, and Gillian Baird. 2009. "Commentary: Effects of Diagnostic Thresholds and Research vs Service and Administrative Diagnosis on Autism Prevalence." International Journal of Epidemiology 38 (5): 1234-38.

$\rightarrow$ Christakis, Nicholas A., and James H. Fowler. 2007. "The Spread of Obesity in a Large Social Network over 32 Years." New England Journal of Medicine 357:370-79.

$\rightarrow$ Clausen, John, and Miriam Yarrow. 1955. "Paths to the Mental Hospital." Journal of Social Issues 11:25-33.

$\rightarrow$ Committee on Children with Disabilities. 2001. "The Pediatrician's Role in the Diagnosis and Management of Autistic Spectrum Disorder in Children." Pediatrics 107:1221-26.

$\rightarrow$ Croen, Lisa A., Judith K. Grether, Jenny Hoogstrate, and Steve Selvin. 2002. "The Changing Prevalence of Autism in California." Journal of Autism and Developmental Disorders 32:207-15.

Dolnick, Edward. 1998. Madness on the Couch: Blaming the Victim in the Heyday of Psychoanalysis. New York: Simon \& Schuster.

$\rightarrow$ Durkin, Maureen S., Matthew J. Maenner, Craig J. Newschaffer, Li-Ching Lee, Christopher M. Cunniff, Julie L. Daniels, Russell S. Kirby, Lewis Leavitt, Lisa Miller, Walter Zahorodny, and Laura A. Schieve. 2008. "Advanced Parental Age and the Risk of Autism Spectrum Disorder.” American Journal of Epidemiology 168:1268-76.

ESRI. 2002-4. Community Sourcebook America with ArcReader. CD-ROM. Redlands, Calif.: ESRI. 
American Journal of Sociology

2007. "Evaluating Population Projections-the Importance of Accurate Forecasting." ESRI White Paper. Redlands, Calif.: ESRI

Eyal, Gil, Brendan Hart, Emine Onculer, Neta Oren, and Natasha Rossi. In press. The Autism Matrix. New York: Polity.

$\rightarrow$ Feld, Scott. 1981. "The Focused Organization of Social Ties." American Journal of Sociology 86:1015-35.

Feld, Scott, and Bernard Grofman. 2009. "Homophily and the Focused Organization of Ties." Pp. 521-43 in The Oxford Handbook of Analytical Sociology, edited by Peter Hedström and Peter Bearman. Oxford: Oxford University Press.

$\rightarrow$ Fernandez, Roberto M., Emilio J. Castilla, and Paul Moore. 2000. "Social Capital at Work: Networks and Employment at a Phone Center." American Journal of Sociology 105:1288-1356.

Festinger, Leon, Stanley Schachter, and Kurt Back. 1950. "The Spatial Ecology of Group Formation." Pp. 33-59 in Social Pressure in Informal Groups: A Study of Human Factors in Housing. New York: Harper.

Fischer, Claude. 1982. To Dwell among Friends. Chicago: University of Chicago Press.

Freidson, Eliot. 1961. Patients'Views of Medical Practice: A Study of Subscribers to a Prepaid Medical Plan in the Bronx. New York: Russell Sage.

GAO (Government Accountability Office). 2006. Federal Autism Activities: Funding for Research Has Increased, but Agencies Need to Resolve Surveillance Challenges. GAO-06-700, Report to the Majority Leader, U.S. Senate. Washington, D.C.: GAO

Goffman, Erving. 1963. Stigma: Notes on the Management of Spoiled Identity. Saddle River, N.J.: Prentice-Hall.

$\rightarrow$ Gonzalez, Marta C., Cesar A. Hidalgo, and Albert-Laszlo Barabasi. 2008. "Understanding Individual Human Mobility Patterns." Nature 453:779-82.

$\rightarrow$ Grandjean, P., and P. J. Landrigan. 2006. "Developmental Neurotoxicity of Industrial Chemicals." Lancet 368:2167-78.

Granovetter, Mark. 1995. Getting a Job: A Study of Contacts and Careers. Chicago: University of Chicago Press.

Grinker, Richard Roy 2007. Unstrange Minds: Remapping the World of Autism. Philadelphia: Basic.

$\rightarrow$ Guest, Avery M., and Susan K. Wierzbicki. 1999. "Social Ties at the Neighborhood Level: Two Decades of GSS Evidence." Urban Affairs Review 35:92-111.

$\rightarrow$ Haynes, Robin M. 1974. "Application of Exponential Distance Decay to Human and Animal Activities." Geografiska Annaler: Series B, Human Geography 56:90-104.

$\rightarrow$ Howlin, Patricia, and Anna Asgharian. 1999. "The Diagnosis of Autism and Asperger Syndrome: Findings from a Survey of 770 Families." Developmental Medicine and Child Neurology 41:834-39.

$\rightarrow$ Howlin, Patricia, and Anna Moorf. 1997. "Diagnosis in Autism: A Survey of over 1200 Patients in the UK." Autism 1:135-62.

$\rightarrow$ Huckfeldt, Robert. 1983. "Social Contexts, Social Networks, and Urban Neighborhoods: Environmental Constraints upon Friendship Choice." American Journal of Sociology 89:651-69.

$\rightarrow$ Kanner, Leo. 1949. "Problems of Nosology and Psychodynamics in Early Childhood Autism." American Journal of Orthopsychiatry 19:416-26.

King, Gary, and Langche Zeng. 1999. "Logistic Regression in Rare Events Data." Working paper. Harvard University, Department of Government.

$\rightarrow$ King, Marissa, and Peter Bearman. 2009a. "Diagnostic Change and Increased Prevalence of Autism." International Journal of Epidemiology 38:1224-34.

.2009b. "The Increased Prevalence of Autism." Working paper. Columbia University, Paul F. Lazarsfeld Center for the Social Sciences.

$\rightarrow$ Klovdahl, Alden, Edward Graviss, and James Muser. 2002. "Infectious Disease Control Combining Molecular Biological and Network Methods." Social Networks and Health 8:73-99. 
$\rightarrow$ Link, Bruce, and Joe Phelan. 2001. "Conceptualizing Stigma." Annual Review of Sociology 27:363-85.

Liu, Ka-Yuet, Noam Zerubavel, and Peter Bearman. 2010. "Social Demographic Change and Autism." Demography, forthcoming.

$\rightarrow$ Mandell, David S., and Raymond Palmer. 2005. "Differences among States in the Identification of Autistic Spectrum Disorders." Archives of Pediatrics and Adolescent Medicine 159:266-69.

Massey, Douglas, and Nancy Denton. 2001. American Apartheid: Segregation and the Making of the Underclass. Cambridge, Mass.: Harvard University Press.

Mazumdar, Soumya, Marissa King, Ka-Yuet Liu, Noam Zerubavel, and Peter Bearman. 2010. "The Spatial Structure of Autism in California, 1993-2001." Health and Place, published online January 22.

$\rightarrow$ McNutt, L. A., C. Wu, X. Xue, and J. P. Hafner. 2003. "Estimating the Relative Risk in Cohort Studies and Clinical Trials of Common Outcomes." American Journal of Epidemiology 157:940-43.

$\rightarrow$ Morenoff, Jeffrey D. 2003. "Neighborhood Mechanisms and the Spatial Dynamics of Birth Weight.” American Journal of Sociology 108:976-1017.

National Center for Charitable Statistics 2008. http://nccs.urban.org. Accessed March $1,2008$.

$\rightarrow$ Nature. 2007. "Autism Speaks: The United States Pays Up." Nature 448:628-29.

$\rightarrow$ Palmer, Raymond F., Stephen Blanchard, Carlos R. Jean, and David S. Mandell. 2005. "School District Resources and Identification of Children with Autistic Disorder." American Journal of Public Health 95:125-30.

$\rightarrow$ Pescosolido, Bernice A. 1992. "Beyond Rational Choice: The Social Dynamics of How People Seek Help.” American Journal of Sociology 97:1096-1138.

Pescosolido, Bernice, and Carol Boyer. 2010. "Understanding the Context and Dynamic Social Processes of Mental Health Treatment." Pp. 420-38 in A Handbook for the Study of Mental Health: Social Contexts, Theories, and Systems, edited by Teresa L. Scheid and Tony N. Brown, 2d ed. New York: Cambridge University Press.

Pescosolido, Bernice A., and Judith A. Levy. 2002. "The Role of Social Networks in Health, Illness, Disease and Healing: The Accepting Present, the Forgotten Past, and the Dangerous Potential for a Complacent Future." Pp. 3-28 in Social Networks and Health, edited by Judith A. Levy and Bernice A. Pescosolido. New York: JAI Press.

$\rightarrow$ Reichenberg, Abraham, Raz Gross, Mark Weiser, Michealine Bresnahan, Jeremy Silverman, Susan Harlap, Jonathan Rabinowitz, Cory Shulman, Dolores Malaspina, Gad Lubin, Haim Y. Knobler, Michael Davidson, and Ezra Susser. 2006. "Advancing Paternal Age and Autism." Archives of General Psychiatry 63:1026-32.

$\rightarrow$ Riley, Steven. 2007. "Large-Scale Spatial-Transmission Models of Infectious Disease." Science 316:1298-1301.

Ritvo, E. R., B. J. Freeman, C. Pingree, A. Mason-Brothers, L. Jorde, W. R. Jenson, W. M. McMahon, P. B. Petersen, A. Mo, and A. Ritvo. 1989. "The UCLA-University of Utah Epidemiologic Survey of Autism: Prevalence." American Journal of Psychiatry 146:194-99.

$\rightarrow$ Rockhill, Beverly, Beth Newman, and Clarice Weinberg. 1998. "Use and Misuse of Population Attributable Fractions." American Journal of Public Health 88:15-19.

Rogers, Everett M. 2003. Diffusion of Innovations. New York: Free Press.

$\rightarrow$ Rutter, Michael. 2006. "Autism: Its Recognition, Early Diagnosis, and Service Implications." Journal of Developmental and Behavioral Pediatrics 27:S54-S58.

$\rightarrow$ Saporito, Salvatore, and Annette Lareau. 1999. "School Selection as a Process: The Multiple Dimensions of Race in Framing Educational Choice." Social Problems 46: 418-39.

Sastry, Narayan, Ann R. Pebley, and Michela Zonta. 2002. "Neighborhood Definitions 


\section{American Journal of Sociology}

and the Spatial Dimension of Daily Life in Los Angeles." Labor and Population Program Working paper 03-2. RAND, Santa Monica, Calif.

Small, Mario L. 2009. Unanticipated Gains: Origins of Network Inequality in Everyday Life. New York: Oxford University Press.

$\rightarrow$ Steenland, Kyle, and Ben Armstrong. 2006. "An Overview of Methods for Calculating the Burden of Disease due to Specific Risk Factors." Epidemiology 17:512-19.

$\rightarrow$ Sullivan, Ruth Christ. 1979. "The Politics of Definition: How Autism Got Included in the Developmental Disabilities Act." Journal of Autism and Developmental Disorders 9:221-31.

Tomz, Michael, Gary King, and Langche Zeng. 1999. ReLogit: Rare Events Logistic Regression. Version 1.1. Cambridge, Mass.: Harvard University.

Trent, James. 1994. Inventing the Feeble Mind: A History of Mental Retardation in the United States. Berkeley and Los Angeles: University of California Press.

$\rightarrow$ Watts, Duncan J., Roby Muhamad, Daniel C. Medina, and Peter S. Dodds. 2005 "Multiscale, Resurgent Epidemics in a Hierarchical Metapopulation Model." Proceedings of the National Academy of Sciences of the United States of America 102: $11157-62$.

Winship, Christopher. 2009. "Time and Scheduling." Pp. 498-520 in The Oxford Handbook of Analytical Sociology, edited by Peter Hedström and Peter Bearman. Oxford: Oxford University Press. 